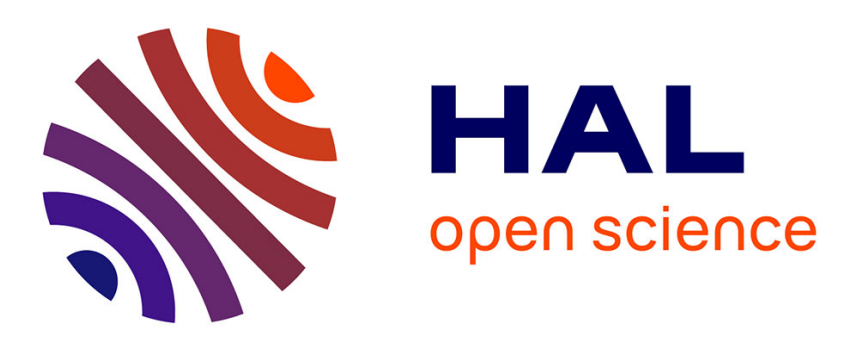

\title{
A Comprehensive Hepatitis C Viral Kinetic Model Explaining Cure
}

Eric Snoeck, Pascal Chanu, Marc Lavielle, Philippe Jacqmin, Niclas Jonsson, Karin Jorga, Timothy Goggin, Joseph Grippo, Shasha Jumbe, Nicolas Frey

\section{- To cite this version:}

Eric Snoeck, Pascal Chanu, Marc Lavielle, Philippe Jacqmin, Niclas Jonsson, et al.. A Comprehensive Hepatitis C Viral Kinetic Model Explaining Cure. Clinical Pharmacology and Therapeutics, 2010, 87 (6), pp.706-713. hal-00637434

\section{HAL Id: hal-00637434 https://hal.science/hal-00637434}

Submitted on 2 Nov 2011

HAL is a multi-disciplinary open access archive for the deposit and dissemination of scientific research documents, whether they are published or not. The documents may come from teaching and research institutions in France or abroad, or from public or private research centers.
L'archive ouverte pluridisciplinaire HAL, est destinée au dépôt et à la diffusion de documents scientifiques de niveau recherche, publiés ou non, émanant des établissements d'enseignement et de recherche français ou étrangers, des laboratoires publics ou privés. 


\section{A comprehensive Hepatitis $\mathbf{C}$ viral kinetic model explaining cure}

2

3 Eric Snoeck ${ }^{1}$, Pascal Chanu ${ }^{2}$, Marc Lavielle ${ }^{3}$, Philippe Jacqmin ${ }^{1}$, E. Niclas Jonsson ${ }^{1}$,

4 Karin Jorga $^{2}$, Timothy Goggin ${ }^{2}$, Joe Grippo ${ }^{2}$, Nelson L. Jumbe ${ }^{2}$, Nicolas Frey ${ }^{2}$ 5

$6 \quad{ }^{1}$ Exprimo NV, Zwaanstraatje 4, B2800, Mechelen, Belgium. ${ }^{2}$ F. Hoffmann-La Roche

7 Ltd., Grenzacherstrasse 124, 4070 Basel, Switzerland. ${ }^{3}$ INRIA Saclay and Department

8 of Mathematics; University Paris-Sud, Orsay, France.

9

10 We propose a model that characterizes and links the complexity and diversity of 11 clinically observed Hepatitis $\mathrm{C}$ viral kinetics to sustained virologic response (SVR, the 12 primary clinical endpoint of Hepatitis C treatment defined as an undetectable viral load 13 at 24 weeks after treatment completion) in Chronic Hepatitis $\mathrm{C}$ (CHC) patients treated 14 with peginterferon $\alpha-2 \mathrm{a} \pm$ ribavirin. New attributes of our Hepatitis $\mathrm{C}$ viral kinetic 15 model are- i) the implementation of a cure/viral eradication boundary, ii) employing all 16 HCV RNA measurements including those below the lower limit of quantification, and 17 iii) implementation of a population modeling approach. The model demonstrated 18 excellent positive (99.3\%) and negative (97.1\%) predictive values for SVR and high sensitivity (96.6\%) and specificity (99.4\%). The proposed viral kinetic model provides a

20 framework for mechanistic exploration of treatment outcome, and permits evaluation of 21 alternative $\mathrm{CHC}$ treatment options to ultimately develop and test hypotheses for 22 personalizing treatments in this disease. 
24 An estimated 170 million people or $2.1 \%$ of the world population are currently infected 25 with hepatitis $\mathrm{C}$ virus (HCV), which is more than four times the number of people 26 living with human immunodeficiency virus HIV (1). The current standard of care (SOC)

27 for Chronic Hepatitis $\mathrm{C}(\mathrm{CHC})$ patients is the combination of pegylated interferon $\alpha$ 28 with ribavirin $(2,3)$. Successful $\mathrm{HCV}$ treatment outcome, i.e. sustained virologic 29 response (SVR), is when a patient's viral load is below the HCV RNA detection limit at 30 a follow-up evaluation 24-weeks following treatment completion. SVR rates of up to $3166 \%$ have been obtained with the optimal regimen of peginterferon $\alpha-2$ a plus ribavirin 32 in treatment-naïve patients in large, randomized, multicentre trials $(4,5)$. Patients 33 infected with the more difficult to treat HCV genotype 1 (G1), which represent about $3470 \%$ of CHC patients in the US (6), are less likely to achieve an SVR than genotype 35 non-1 (Gn1) infected patients. Approximately 50\% of HCV G1 infected patients 36 achieved an SVR when treated with peginterferon $\alpha-2 a$ plus ribavirin, whereas 37 approximately $80 \%$ of HCV Gn1-infected patients achieved an SVR despite receiving a shorter treatment duration and a lower ribavirin dose (5). Thus, HCV patients represent 39 a population with continued unmet medical need, having the potential to achieve a 40 higher SVR rate through optimized treatment approaches.

41 Modeling hepatitis $\mathrm{C}$ virus (HCV) dynamics during therapy has led to important 42 insights into the life cycle of HCV elucidating the kinetic parameters governing viral 43 infection and hepatocyte death, the antiviral effects of interferons, and how ribavirin 44 impacts HCV treatment (7). Models of HCV kinetics have provided a means to compare 45 different treatment regimens and outcomes in different patient populations (8). A model 46 of HCV infection was originally proposed by Neumann et al. (9) who adapted a model 47 of HIV infection $(10,11)$. The Neumann model adequately describes typical short-term 
therapy outcome characterized by an initial rapid viral decline followed by a second slower decline until HCV RNA becomes undetectable $(12,13)$. This model has therefore been frequently used to describe viral load profiles after short-term treatment $(8,14,15)$.

51 However, after current long-term SOC treatment, the virus is not eradicated in all CHC

52 patients (5). In the patients who do not achieve SVR (i.e the virus is not eradicated), 53 viral load either rebounds to pretreatment levels during therapy (breakthrough), or returns to pretreatment levels upon cessation of therapy (relapse) (13). These two phenomena, and crucially, an SVR cannot be described by the Neumann model (13), and are the primary reason why early viral response does not uniformly predict the

57 clinical endpoint. Finally, and most importantly, previous analyses have used a naïve 58 method of handling the HCV RNA measurements below the lower limit of 59 quantification (LLOQ) by omission of all these measurements even though these values 60 contain critical information regarding long-term treatment outcome.

61 In this communication, we propose a novel approach of modelling the viral kinetics in 62 Hepatitis C. Firstly, a non-linear mixed effects model was developed by maximum 63 likelihood estimation (MLE) of the parameters using the extended stochastic 64 approximation expectation-maximization (SAEM) algorithm as implemented in the 65 MONOLIX software (16). Individual long-term HCV kinetic profiles of 2,100 CHC 66 patients treated with peginterferon $\alpha-2 \mathrm{a}$ alone or in combination with ribavirin using a 67 wide spectrum of dosing regimens were simultaneously described. Secondly, HCV 68 RNA measurements below the LLOQ were included. The proposed model permits the 69 distinction between SVR and LLOQ by including censored data residing between the 70 HCV RNA LLOQ and the irrevocable lower boundary of zero. Thirdly, cure or 71 complete virion eradication was determined from viral kinetics by implementation of a 
72 viral eradication boundary. At the time point at which treatment drives the system to

73 less than one infected hepatocyte, the production of virions was set to zero. Modeling

74 results characterizing differences between patients having an SVR and those failing 75 treatment were explored in order to derive mechanistic hypotheses underpinning 76 treatment failure or success.

77

\section{RESULTS}

79 Parameters of the model were estimated with good precision (Table 1). The typical 80 value of the basic reproduction number $R_{0}$ was estimated to be 7.2 with an inter81 individual variability (IIV) of $137 \% \mathrm{CV}$. The relatively large IIV likely reflects the large 82 intrinsic biological difference in $\mathrm{CHC}$ disease. $R_{0}$ represents relative drug-effect 83 distance from the treatment intervention goal, which is to drive the reproduction number 84 during treatment $\left(R_{T}\right)$ below 1 (Supplementary text note 2 online), in order to increase 85 the likelihood of attaining SVR (i.e. cure, defined as I $<1$ infected hepatocyte). 86 Inspection of the individual parameter estimates in patients experiencing a breakthrough 87 during therapy indeed showed that the administered drug therapy failed to decrease the reproduction number $\left(R_{T}\right)$ below $1(17,18)$. The maximum hepatocyte proliferation rate (r) was $0.00562 \mathrm{day}^{-1}$, and simulations based on this $r$ revealed that the predicted liver regeneration matched well with the increase in original liver volume in 51 donors as

91 measured 1 year after providing right-lobe liver grafts [Supplementary text note 3 92 online (19)]. The typical value of the virion production rate $p$ was 25.1 virions $^{\cdot}$ day $^{-1}$ and 93 the free virion clearance rate $c$ was estimated to be 4.53 day $^{-1}$, corresponding to a free 94 virion half-life of 3.7 hours. This half-life lies within the previously reported range of 95 1.5-4.6 hours $(12,13)$. Free virion clearance rate was found not to be influenced by HCV 
114 kinetic models as a $\sigma^{2}$ of 0.38 was obtained previously in a similar analysis of HIV viral 115 load data (22).

116

\section{Model evaluation and qualification}

118 The goodness of fit assessment revealed that the individual viral load profiles are well

119 described by the model (Supplementary text note 4 online). Population based

genotype. In contrast, the infected cell death rate $(\delta)$ appeared to be dependent on HCV genotype, and the typical value was estimated to be 0.139 day $^{-1}$ in genotype- 1 infected patients and 0.192 day $^{-1}$ in patients infected with HCV Gn1 (Table 1). These estimates are in line with previously reported values of $\delta(20)$. The higher $\delta$ in HCV Gn1 infected patients may indicate an enhanced immunological response and is in line with the previous finding that a fast viral decay early in treatment correlates with SVR (20). Also the typical value of the $E D_{50_{P E G}}$ was found to be lower in $\mathrm{HCV}$ Gn1 patients as compared to patients infected with $\mathrm{HCV}$ G1, confirming the higher antiviral effectiveness of peginterferon $\alpha-2 \mathrm{a}$ in blocking virion production in Gn1 patients [Table 1 and (20)]. The $E D_{50_{R B V}}$ was estimated to be $14.4 \mathrm{mg} \cdot \mathrm{kg}^{-1} \cdot \mathrm{day}^{-1}$, which corresponds to rendering a fraction of $40-60 \%$ of the virions non-infectious for a standard ribavirin treatment of 1,000/1,200 $\mathrm{mg}$ per day (see equation 6). The anti-viral effect decay constant $(K)$ was estimated to be 0.0238 day $^{-1}$, which corresponds to a halflife of approximately 29 days. As the terminal half-life after multiple dosing of peginterferon $\alpha-2 \mathrm{a}$ is approximately $160 \mathrm{~h}$ and that of ribavirin is approximately 12 days (21), the anti-viral effect decay constant may describe both pharmacokinetic and pharmacodynamic processes. Finally, the variance of the residual error $\left(\sigma^{2}\right)$ was estimated to be 0.260 . This residual error is relatively high but not uncommon for viral 
120 diagnostics were also used, but are not easily interpretable unless simulated reference

121 graphs from the true model are used for comparison [Supplementary text note 4 online

122 (23)]. A selection of 12 individual viral load profiles shows that the HCV viral kinetic

123 model is able to not only describe the initial decreases in viral load over the first month,

124 but also the typical phenomena observed after longer-term therapy (Figure 3). The

125 model provided satisfactory positive (99.3\%) and negative (97.1\%) predictive values for

126 SVR combined with a high sensitivity (96.6\%) and specificity (99.4\%)

127 [Supplementary text note 5 online].

128 The predictive performance of the model was assessed by a model evaluation procedure

129 using the design and data of a large clinical trial not included in the model building

130 dataset (4). The model was successfully qualified for further simulations as the

131 predicted range of SVR rate in HCV G1 and Gn1 infected patients receiving 48 weeks

132 of treatment with peginterferon $\alpha-2 \mathrm{a}$ alone or in combination with ribavirin matched

133 well with the observed SVR rate in this study (Figure 5).

\section{Discussion}

136 The multi-dimensional interactions between HCV virus, host and drug are highly non-

137 linear and equilibrium outcomes quickly become counter-intuitive (24). Here, we

138 propose a population approach using MLE by the extended SAEM algorithm as

139 implemented in the MONOLIX software (16), to simultaneously describe individual

140 long-term $\mathrm{HCV}$ kinetic profiles of 2,100 CHC patients treated with peginterferon $\alpha$-2a

141 alone or in combination with ribavirin. The four ordinary differential equations (ODE's)

142 of the HCV viral kinetic model (equations 1-4) were implemented in MONOLIX. HCV

143 viral kinetic models including ODE's have been previously used for exploratory 
144 simulations $(17,25)$, however not for simultaneously fitting the complexity and diversity

145 of clinically observed HCV viral kinetics.

146 The proposed model addresses the host-virus-drug interaction by advancing previously

147 known and novel ideas from a population perspective, simultaneously analyzing a wide

148 spectrum of treatment regimens (drug combinations, drug doses, schedule and treatment

149 durations), incorporating left-censored data previously largely excluded from analysis,

150 and implementing a viral eradication cure boundary to link viral kinetics to clinical

151 outcome (i.e. SVR). The final viral kinetic model was qualified using internal and

152 external datasets, including HCV G1 and Gn1 infected patients, and demonstrated

153 positive and negative predictive values as well as sensitivity and specificity exceeding

$15496 \%$.

155 In clinical practice, milestone target treatment strategies, i.e., rapid virologic response

156 (RVR)- defined as attainment of undetectable HCV RNA level by week 4 of therapy

157 (26,27), or early virologic response (EVR)- defined $\geq 2 \log$ reduction or undetectable

158 serum HCV RNA at week 12 of treatment, have been proposed to optimize SVR rates

159 by modifying treatment duration. However, these early treatment response landmarks

160 (regardless of time point) do not uniformly predict SVR because viral load either

161 rebounds to pretreatment levels during therapy (breakthrough), or returns to

162 pretreatment levels upon cessation of therapy (relapse). This observations leads to two

163 conclusions, (i) the relationship between RVR/EVR and SVR is correlative but not

164 prescriptive, and (ii) excluding HCV RNA measurements below the LLOQ (i.e., left-

165 censoring) likely biases SVR predictions. An extension of the SAEM algorithm as

166 implemented in the MONOLIX software handles left-censored data in nonlinear mixed-

167 effects models with computational efficiency (22). Comparison with classical methods 
168 of handling missing data shows that the extended SAEM algorithm is less biased than

169 excluding subjects with censored measurements, omission of all censored data points,

$170 \mathrm{and} /$ or imputation to half the quantification limit for the first point below the LLOQ

171 with omission of subsequent missing data (28). Furthermore, the extended SAEM

172 algorithm has been demonstrated to be more efficient and/or less biased than

173 linearization or Monte Carlo approximation of the expectation step applied to censored

174 values (22).

175 The implementation of the cure boundary in the viral kinetic model is physiologically

176 based and consistent with the primary goal of HCV therapy, which is to completely

177 eradicate the virus. The final viral kinetic model was implemented as a two state system.

178 The off state (null virion production) was triggered when there was less than one

179 infected hepatocyte in the total plasma and extracellular fluid volume of distribution

180 thereby resulting in cure/SVR. The on state (constitutive virion production),

181 inadvertedly returns the patient to full blown disease when even a minute fraction of one

182 infected hepatocyte remains.

183 A comparison of the individual parameter estimates between patients with and without

184 an SVR reveals that $R_{0}$ and $E D_{50_{P E G}}$ are generally lower in SVR patients (Figure 4). A

185 relatively low $R_{0}$ prior to treatment and a relatively high inhibition of the virion

186 production increase the likelihood of $R_{T}<1$ during treatment and will thus increase the

187 likelihood of SVR.

188 Inspection of the individual parameter estimates in patients experiencing a breakthrough

189 during therapy indeed showed that the administered drug therapy failed to decrease the

$190 R_{T}$ below $1(17,18)$. According to our modeling assumptions, a treatment with either

191 higher doses or a combination treatment with new drugs may be an option in these 
192 patients in order to drive $R_{T}$ below 1 . The conditional explanation in patients relapsing

193 after the end of treatment may be twofold: i) on the one hand, relapsing patients may

194 have had a $R_{T}<1$ during treatment, but were not treated long enough to cross the cure

195 boundary of $\mathrm{I}<1$ cell, so that the viral load quickly returned back to baseline at the end

196 of therapy, or ii) drug therapy may have failed to decrease the $R_{T}$ below 1 (inadequate

197 efficacy). Extended treatment duration at the same drug combination, dose and schedule

198 in relapsing patients may therefore be an option in the former situation but not in the

199 latter. Based on these hypotheses, individual treatments may be optimized when the 200 individual $R_{0}$ and inhibition of the virion production are pre-determined or determined 201 early at treatment onset. The interplay between treatment duration, dose and schedule, 202 and/or sensitivity of hitting the cure boundary after high dose induction is yet to be fully 203 elucidated.

204 In our model-based analysis, the free virion clearance rate $(c)$ did not appear to be a 205 prognostic factor for SVR (Figure 4), whereas the death rate of infected cells $(\delta)$ was 206 found to be generally higher in SVR patients indicating these patients may have an 207 enhanced immunological response and thus a higher likelihood of viral eradication.

208 Our proposed viral kinetic model is a simplification of the complex interaction between 209 host, infected hepatocytes, virus, and mechanisms of drug action and required fixing of 210 several liver physiology parameters to biologically justifiable values. Furthermore, the 211 combination of peginterferon $\alpha-2 \mathrm{a}$ and ribavirin is assumed to inhibit in a multiplicative 212 way the virion production $(p)$ according to $E_{\max }$ dose-response relationships. While 213 some confidence in the predictive performance of the model is derived from the 214 qualification exercise described above, complete understanding of the implications of 215 these assumptions is not fully understood and should be further explored, particularly in 
216 the case where the model would be used to explore the efficacy of new drugs in

217 combination with SOC. Another limitation of our current model is the fact that dose was

218 used as the pertubation to the system. Since HCV SOC pharmacotherapy has been

219 established through empirical study over a decade, investigation of schedule

220 dependence was not considered as primary to our objectives. This implies that a

221 pharmacokinetic model component will have to be added to the current model for the

222 evaluation of schedule dependence and/or adherence, especially for drugs with shorter

223 pharmacokinetic half-lives that are being developed.

224 In summary, our population HCV viral kinetic model was able to adequately describe

225 all individual long-term viral load profiles of 2,100 CHC patients receiving chronic

226 treatment of peginterferon $\alpha-2 \mathrm{a}$ alone or in combination with ribavirin. The model

227 provides new insights and explanations for typical phenomena observed in the clinic

228 such as breakthrough during therapy, relapse after stopping therapy and cure (or SVR).

229 Simulations based on our model may help to better understand current treatment success

230 and failure, and can also be used to predict and evaluate the efficacy of alternative

231 treatment options (e.g. alternative doses, durations and, with additional assumptions-

232 new drug combinations) in the overall CHC patient population. This will be described in

233 a follow-up communication. The proposed viral kinetic model provides a framework for

234 developing and testing hypotheses for evaluating new antiviral agents and personalizing

235 CHC treatments that would ultimately need to be validated in well designed clinical 236 trials.

\section{METHODS}

\section{Patients and Data}


240 Data from one phase-II study and four phase-III studies of peginterferon $\alpha-2 \mathrm{a}$ (40KD)

241 (Pegasys $\left.^{\circledR}\right)$ alone or in combination with ribavirin $\left(\right.$ Copegus $\left.^{\circledR}\right)$ were pooled. All patients

242 were required to have histologically and serologically proven CHC. The complete

243 inclusion and exclusion criteria, study design, and primary results have been published

244 elsewhere $(5,29-32)$. A total of 2,100 CHC patients were included in the final database.

245 Serum HCV RNA (COBAS AMPLICOR ${ }^{\mathrm{T} M}$ HCV Test, version 2.0) was measured at

246 specific time points during treatment and during the 24-week untreated follow-up

247 period. All available 21,284 HCV RNA measurements, of which 59\% were below the

248 LLOQ, were modeled by accounting for the left-censoring in the analysis. The LLOQ of 249 the two different assays used were $50 \mathrm{IU} / \mathrm{mL}$ and $600 \mathrm{IU} / \mathrm{mL}(33)$.

250

\section{$251 \quad$ HCV viral kinetic model}

252 The viral kinetic model (equations 1-4) extends the original Neumann (9) model, to 253 include important contributions by Dahari et al. (density dependent proliferation of 254 hepatocytes $[r], 17)$ and Pomfret et al. (hepatocyte intrinsic production, 19). Treatment 255 effect of peginterferon $\alpha-2 \mathrm{a}[\varepsilon]$ and the effect of ribavirin rendering a fraction of newly 256 produced virions non-infectious $[\rho](7)$ was implemented on the virion production rate 257 ( $p$ ). The model structure of the viral kinetic model (Figure 1) is described by the 258 following mass balance equations:

$$
\begin{aligned}
& 259 \frac{d T}{d t}=s+r \cdot T \cdot\left(1-\frac{T+I}{T_{\max }}\right)-d \cdot T-\beta \cdot V_{I} \cdot T \\
& 260 \frac{d I}{d t}=\beta \cdot V_{I} \cdot T+r \cdot I \cdot\left(1-\frac{T+I}{T_{\max }}\right)-\delta \cdot I \\
& 261 \frac{d V_{I}}{d t}=(1-\rho) \cdot(1-\varepsilon) \cdot p \cdot I-c \cdot V_{I}
\end{aligned}
$$


$262 \quad \frac{d V_{N I}}{d t}=\rho \cdot(1-\varepsilon) \cdot p \cdot I-c \cdot V_{N I}$

263 where, infectious $\mathrm{HCV}$ virions $\left(V_{I}\right)$ infect target cells (uninfected hepatocytes) [T], 264 creating productively infected cells $(I)$ at a rate $\beta \cdot V_{I} T$. Uninfected hepatocytes are 265 produced at rate $s$ and die at rate $d$. Infected hepatocytes die at rate $\delta$. Similar to Dixit et 266 al. (7), it is assumed that infectious $\left(V_{I}\right)$ and non-infectious $\left(V_{N I}\right)$ virions are produced 267 from infected hepatocytes at rate $p$ and cleared at rate $c$. The measured viral load $(V)$ is 268 expressed in $\mathrm{IU} / \mathrm{mL}$, representing the sum of infectious and non-infectious virions $V=$ $269 V_{I}+V_{N I}$. The model was further extended with $E_{\max }$ dose-response models describing 270 the dose-dependent effects of peginterferon $\alpha-2 \mathrm{a}$ and ribavirin:

$271 \quad \varepsilon=\frac{\text { Dose }_{P E G}}{E D_{50_{P E G}}+\text { Dose }_{P E G}}$

$272 \rho=\frac{\text { Dose }_{R B V}}{E D_{50_{R B V}}+\text { Dose }_{R B V}}$

273 where Dose $_{P E G}$ is the weekly subcutaneous dose of peginterferon $\alpha$-2a and $E D_{50_{P E G}}$ is

274 the estimated weekly dose of peginterferon $\alpha$-2a resulting in a $50 \%$ inhibition of the 275 virion production. Similarly, Dose $_{R B V}$ is the daily dose of ribavirin per kg body weight 276 and $E D_{50_{R B V}}$ is the estimated daily dose in $\mathrm{mg} / \mathrm{kg}$ rendering $50 \%$ of the virions non277 infectious. Dose $e_{R B V}$ and $E D_{50_{R B V}}$ were expressed as $\mathrm{mg} / \mathrm{kg}$ as ribavirin is dosed by body 278 weight and ribavirin in $\mathrm{mg} / \mathrm{kg}$ has been previously found to be a prognostic factor for 279 SVR (34).

280 The implementation of a cure/viral eradication boundary represents a milestone 281 contribution in enabling linking the complexity and diversity of clinically observed 282 Hepatitis C viral kinetics to SVR. The cure boundary was based on the assumption that 
283 virion production $(p)$ should cease when all infected cells are cleared, i.e., when there is 284 less that 1 infected cell in the total plasma and extracellular fluid volume of 285 approximately $13.5 \cdot 10^{3} \mathrm{~mL}$. At the time point at which treatment anti-viral effect drove 286 the system to less than one infected hepatocyte, the virion production $p$ was set to zero 287 (off state), resulting in a model cure/SVR [Supplementary text note 1 online (35)]. 288 Exploratory simulations without this additional model component of cure predicted 289 rapid viral load return to baseline in all $\mathrm{CHC}$ patients when treatment was stopped 290 [Supplementary text note 1 online (35)], while in reality the virus is eradicated after 291 the current standard treatment of care in the majority of Gn1 infected patients and 292 approximately half of the HCV G1 patients and approximately (5).

293 A fundamental parameter of the viral kinetic model is the estimated basic reproduction 294 number $\left(R_{0}\right)$ [Supplementary text note 2 online (18)]. Previously, it was shown that the 295 reproduction number in the presence of an inhibitor $\left(R_{T}\right)$ is $(36)$ :

$296 \quad R_{T}=R_{0} \cdot\left(1-\varepsilon_{T}\right)$

297 where $\varepsilon_{T}$ is the total treatment-induced inhibition of the virion production. As infection 298 in the presence of an inhibitor has been shown to be cleared when $R_{T}<1(36), \varepsilon_{T}$ 299 combined with $R_{0}$ are thus important predictors for a successful drug therapy. For this 300 reason, our model was parameterized in terms of $R_{0}$, by using the following equation for $301 \quad R_{0}(18)$ :

$302 \quad R_{0}=\frac{p \cdot \beta \cdot s}{c \cdot \delta \cdot d}$

303 Finally, drug-effect after stopping treatment was described by an exponential decay 304 function $\left(e^{-K \cdot t}\right.$, Figure 2), where $K$ is the estimated antiviral-effect decay constant and $t$ 305 the time from the end of treatment. Without the inclusion of this exponential decay 
306 function, the viral load in relapsing patients after stopping therapy appeared to return

307 too rapidly to pre-treatment values

308

309 Model assumptions

310 Currently available data did not allow the estimation of all parameters of the declared

311 viral kinetic model due to issues of mathematical identifiability. For this reason, a 312 number of system/physiological parameters were fixed to biologically justifiable values.

313 The maximum number of hepatocytes present in an individual liver was assumed to be $3142.50 \cdot 10^{11}$ hepatocytes (37). As HCV RNA is distributed in plasma and extracellular 315 fluids with a volume of approximately $13.5 \cdot 10^{3} \mathrm{~mL}(38)$, the maximum number of 316 hepatocytes $\left(T_{\max }\right)$ was assumed to be $18.5 \cdot 10^{6}$ cells $\cdot \mathrm{mL}^{-1}(12)$. Assuming a hepatocyte 317 turnover in a healthy liver of 300 days (39), the death rate of target cells $(d)$ was set to $3181 / 300$ day $^{-1}$, and therefrom $\left(T_{\max } \cdot d\right)$ the production of new hepatocytes in the absence of 319 liver disease $(s)$ could be assumed to be $61.7 \cdot 10^{3}$ cells $\cdot \mathrm{mL}^{-1}$ days $^{-1}(12)$. Estimated 320 proliferation rates were set to be equal across infected and uninfected hepatocytes due to 321 a lack of direct information to the contrary.

322 Non-linear mixed effects models comprise of a combination of fixed and random 323 effects. Individual parameters $\left(P A R_{i}\right)$ in such a model are assumed to be log-normally 324 distributed and can be described by:

$325 P A R_{i}=\theta \cdot e^{\eta_{i}}$

326 where, subscript $i$ denotes individual, the fixed effects parameter $\theta$ represents the 327 median (typical) value of the parameter in the population, and $\eta_{i}$ is the random effect 328 accounting for the individual difference from the typical value. The $\eta_{i}$ values are 329 assumed to be normally distributed in the population with a mean of zero and an 
330 estimated variance of $\omega^{2}$. Individual parameter estimates are used to predict the viral

331 load in an individual $i$ at a certain point in time $j\left(V_{\text {pred, } i j}\right)$. The measured viral load data

$332\left(V_{o b s, i j}\right)$ were $\log _{10}$-transformed for the analysis in order to be able to handle the wide

333 range of viral load observations, and an additive residual error model was used for the

$334 \log _{10}$-transfomed viral load data:

$335 \log _{10} V_{o b s, i j}=\log _{10} V_{p r e d, i j}+\varepsilon_{i j}$

336 The $\varepsilon_{i j}$ values are assumed to be normally distributed with a mean of zero and an

337 estimated variance $\sigma^{2}$. The $\omega^{2}$ quantifies the inter-individual variability (IIV) and the $\sigma^{2}$ 338 quantifies the residual variability.

339 Estimated fixed effects parameters were $R_{0}, p, c, \delta$, liver proliferation rate $r$

340 [Supplementary text note 3 online (17)], $E D_{50_{P E G}}, E D_{50_{R B V}}$ and $K$. IIV was incorporated 341 on the parameters $R_{0}, c, \delta$ and $E D_{50_{P E G}}$.

\section{Parameter estimation}

344 Population parameters of our HCV viral kinetic model were estimated using MLE by 345 the SAEM algorithm for hierarchical nonlinear mixed effects model analysis $(40,41)$. 346 Individual parameters were obtained by computing for each individual patient the so347 called Maximum A Posteriori (MAP) esimate, which maximizes the conditional 348 distribution of the individual parameters using the MLE of the population parameters 349 computed previously with the SAEM algorithm (40). SAEM is a powerful algorithm for 350 MLE in complex models, including dynamic models defined by a system of ODE's. 351 Furthermore, the left-censored data are properly handled by the extended SAEM 352 algorithm for MLE as described by Samson et al. (22). The extended SAEM algorithm 
353 for MLE is implemented in the MONOLIX software, available on the author's website

354 (16). We used version 2.4 of MONOLIX.

\section{Model evaluation and qualification}

357 Goodness of fit was assessed by the method of simulating from the final model and re358 fitting (23). Since by definition, the proposed model does not characterize SVR directly, 359 but SVR is derived from crossing the model cure boundary, the predictive performance 360 of the model in correctly classifying patients into SVR or non-SVR, which is considered 361 one of the core utilities of the model, could be assessed by calculating the sensitivity 362 and specificity $(42,43)$ without confounding bias. The predictive performance of the 363 model was assessed by a model evaluation procedure using the design and data of a 364 large clinical trial not included in the model building dataset. In this trial, $180 \mu \mathrm{g}$ 365 peginterferon $\alpha-2 \mathrm{a}$ was administered once weekly for 48 weeks, alone or in 366 combination with daily 1,000 or $1,200 \mathrm{mg}$ ribavirin (4). Dropout rates in the simulated 367 cohort were matched to historical data by random assignment and defining dropouts as 368 non-SVR. The uncertainty of the observed SVR rates was quantified by 400 bootstrap 369 samples and compared to observed SVR rates in the trial.

370

\section{ACKNOWLEDGMENTS}

372 We wish to pay tribute to the 2,100 anonymized patients whose data is included in this 373 analysis, physicians and nurses who took care of them, and the Pegasys ${ }^{\circledR}$ Life Cycle

374 Team for their vision and support in the development of this model. We thank Frank 375 Duff, Annabelle Lemenuel and Rohit Kulkarni for scientific input and editorial 
376 assistance, and Sharon Lim and Marlene Hering for help in the preparation of this 377 manuscript.

378

379 Financial disclosure: P. Chanu, K. Jorga, T. Goggin, J. Grippo, N. L. Jumbe, and N. 380 Frey are F. Hoffman-La Roche Ltd employees. E. Snoeck, P. Jacqmin, and N. Jonsson 381 are compensated F. Hoffman-La Roche Ltd. consultants. M. Lavielle is the developer of 382 MONOLIX and has no conflict of interest. 


\section{REFERENCES AND NOTES}

1 World Health Organization. Hepatitis C. Available at http://www.who.int/mediacentre/factsheets/fs164/en/ Last accessed 15 September 2008.

2 National Institutes of Health, Hepatology 36, S3 (2002).

3 Strader DB, Wright T, Thomas DL, Seeff LB; American Association for the Study of Liver Diseases. Diagnosis, management, and treatment of hepatitis C. Hepatology. 2004 Apr;39(4):1147-71.

4 Fried MW, Shiffman ML, Reddy KR, Smith C, Marinos G, Gonçales FL Jr, Häussinger D, Diago M, Carosi G, Dhumeaux D, Craxi A, Lin A, Hoffman J, Yu J. Peginterferon alfa-2a plus ribavirin for chronic hepatitis $\mathrm{C}$ virus infection. N Engl J Med. 2002 Sep 26;347(13):975-82.

5 Hadziyannis SJ, Sette H Jr, Morgan TR, Balan V, Diago M, Marcellin P, Ramadori G, Bodenheimer H Jr, Bernstein D, Rizzetto M, Zeuzem S, Pockros PJ, Lin A, Ackrill AM; PEGASYS International Study Group. Peginterferon-alpha2a and ribavirin combination therapy in chronic hepatitis $\mathrm{C}$ : a randomized study of treatment duration and ribavirin dose. Ann Intern Med. 2004 Mar 2;140(5):346-55.

6 Zein NN, Rakela J, Krawitt EL, Reddy KR, Tominaga T, Persing DH. Hepatitis C virus genotypes in the United States: epidemiology, pathogenicity, and response to interferon therapy. Collaborative Study Group. Ann Intern Med. 1996 Oct $15 ; 125(8): 634-9$.

7 Dixit NM, Layden-Almer JE, Layden TJ, Perelson AS. Modelling how ribavirin improves interferon response rates in hepatitis C virus infection. Nature. 2004 Dec $16 ; 432(7019): 922-4$. 
8 Perelson AS, Herrmann E, Micol F, Zeuzem S. New kinetic models for the hepatitis C virus. Hepatology. 2005 Oct;42(4):749-54.

9 Neumann AU, Lam NP, Dahari H, Gretch DR, Wiley TE, Layden TJ, Perelson AS. Hepatitis $\mathrm{C}$ viral dynamics in vivo and the antiviral efficacy of interferon-alpha therapy. Science. 1998 Oct 2;282(5386):103-7

10 Perelson AS, Neumann AU, Markowitz M, Leonard JM, Ho DD. HIV-1 dynamics in vivo: virion clearance rate, infected cell life-span, and viral generation time. Science. 1996 Mar 15;271(5255):1582-6.

11 Wei X, Ghosh SK, Taylor ME, Johnson VA, Emini EA, Deutsch P, Lifson JD, Bonhoeffer S, Nowak MA, Hahn BH, et al. Viral dynamics in human immunodeficiency virus type 1 infection. Nature. 1995 Jan 12;373(6510):117-22.

12 Colombatto P, Civitano L, Oliveri F, Coco B, Ciccorossi P, Flichman D, Campa M, Bonino F, Brunetto MR. Sustained response to interferon-ribavirin combination therapy predicted by a model of hepatitis C virus dynamics using both HCV RNA and alanine aminotransferase. Antivir Ther. 2003 Dec;8(6):519-30.

13 Zeuzem S. The kinetics of hepatitis C virus infection. Clin Liver Dis. 2001 Nov;5(4):917-30

14 Layden JE, Layden TJ. Viral kinetics of hepatitis C: new insights and remaining limitations. Hepatology. 2002 Apr;35(4):967-70.

15 Layden-Almer JE, Cotler SJ, Layden TJ. Viral kinetics in the treatment of chronic hepatitis C. J Viral Hepat. 2006 Aug;13(8):499-504

16 http://www.monolix.org/

17 Dahari H, Lo A, Ribeiro RM, Perelson AS. Modeling hepatitis C virus dynamics: liver regeneration and critical drug efficacy. J Theor Biol. 2007;247(2):371-81. 
18 Callaway DS, Perelson AS. HIV-1 infection and low steady state viral loads. Bull Math Biol. 2002 Jan;64(1):29-64.

19 Pomfret EA, Pomposelli JJ, Gordon FD, Erbay N, Lyn Price L, Lewis WD, Jenkins RL. Liver regeneration and surgical outcome in donors of right-lobe liver grafts. Transplantation. 2003 Jul 15;76(1):5-10.

20 Neumann AU, Lam NP, Dahari H, Davidian M, Wiley TE, Mika BP, Perelson AS, Layden TJ. Differences in viral dynamics between genotypes 1 and 2 of hepatitis C virus. J Infect Dis. 2000 Jul;182(1):28-35. Epub 2000 Jul 6.

21 US FDA label information of Pegasys and Copegus. Available at: http://www.fda.gov

22 Samson A, Lavielle M, Mentré F. Extension of the SAEM algorithm to leftcensored data in nonlinear mixed-effects model: Application to HIV dynamics model. Computational Statistics \& Data Analysis. Volume 51, Issue 3, 1 December 2006, Pages 1562-1574.

23 Karlsson MO, Savic RM. Diagnosing model diagnostics. Clin Pharmacol Ther. 2007;82:17-20.

24 Bernardin F, Tobler L, Walsh I, Williams JD, Busch M, Delwart E. Clearance of hepatitis C virus RNA from the peripheral blood mononuclear cells of blood donors who spontaneously or therapeutically control their plasma viremia. Hepatology. 2008 May;47(5):1446-52.

25 Wodarz D. Mathematical models of immune effector responses to viral infections: virus control versus the development of pathology. J. Comp. Appl. Math. 2005; 184:301-319. 
26 Dienstag JL, McHutchison JG. American Gastroenterological Association technical review on the management of hepatitis C. Gastroenterology 2006; 130:231-64)

27 Strader DB, Wright T, Thomas DL, Seeff LB. Diagnosis, management, and treatment of hepatitis C. Hepatology. 2004; 39:1147-71.

28 Samson A, Lavielle M, Mentré F. The SAEM algorithm for group comparison tests in longitudinal data analysis based on non-linear mixed-effects model. Stat Med. 2007 Nov 30;26(27):4860-75.

29 Heathcote EJ, Shiffman ML, Cooksley WG, Dusheiko GM, Lee SS, Balart L, Reindollar R, Reddy RK, Wright TL, Lin A, Hoffman J, De Pamphilis J. Peginterferon alfa-2a in patients with chronic hepatitis $\mathrm{C}$ and cirrhosis. $\mathrm{N}$ Engl $\mathrm{J}$ Med. 2000 Dec 7;343(23):1673-80.

30 Zeuzem S, Feinman SV, Rasenack J, Heathcote EJ, Lai MY, Gane E, O’Grady J, Reichen J, Diago M, Lin A, Hoffman J, Brunda MJ. Peginterferon alfa-2a in patients with chronic hepatitis C. N Engl J Med. 2007;357(2):124-34.

31 Reddy KR, Wright TL, Pockros PJ, Shiffman M, Everson G, Reindollar R, Fried MW, Purdum PP, Jensen D, Smith C, Lee WM, Boyer TD, Lin A, Pedder S, DePamphilis J. Efficacy and safety of pegylated (40-kd) interferon alfa-2a compared with interferon alfa-2a in noncirrhotic patients with chronic hepatitis $\mathrm{C}$. Hepatology 2001;33(2)433-8.

32 Pockros PJ, Carithers R, Desmond P, Dhumeaux D, Fried MW, Marcellin P, Shiffman ML, Minuk G, Reddy KR, Reindollar RW, Lin A, Brunda MJ; PEGASYS International Study Group. Efficacy and safety of two-dose regimens of peginterferon alpha-2a compared with interferon alpha-2a in chronic hepatitis $\mathrm{C}$ : a multicenter, randomized controlled trial. Am J Gastroenterol. 2004 Jul;99(7):1298-305. 
33 Lee SC, Antony A, Lee N, Leibow J, Yang JQ, Soviero S, Gutekunst K, Rosenstraus M. Improved version 2.0 qualitative and quantitative AMPLICOR reverse transcription-PCR tests for hepatitis $\mathrm{C}$ virus RNA: calibration to international units, enhanced genotype reactivity, and performance characteristics. J Clin Microbiol. 2000 Nov;38(11):4171-9.

34 Snoeck E, Wade JR, Duff F, Lamb M, Jorga K. Predicting sustained virological response and anaemia in chronic hepatitis $\mathrm{C}$ patients treated with peginterferon alfa-2a (40KD) plus ribavirin. Br J Clin Pharmacol. 2006;62(6):699-709.

35 CPT Supplementary online material

36 Jacqmin P et al., submitted for publication in J. Pharmacokinet. Pharmacodyn.

37 Sherlock S, Dooley J. in Disease of the Liver and Biliary system (Blackwell Science, 1998), pp 8.

38 Liou TC, Chang TT, Young KC, Lin XZ, Lin CY, Wu HL. Detection of HCV RNA in saliva, urine, seminal fluid and ascites. J Med Virol. 1992;37(3), 203-9.

39 Mc Sween RNM, Anthony PP, Scheuer PJ, Pathology of the Liver - Second edition Churchill Livingstone, 1987.

40 Delyon B, Lavielle M, Moulines E. Covergence of a stochastic approximation version of the EM algorithm. Ann. Statist. 1999; 27: 94-128.

41 Kuhn E, Laveille M. Maximum likelihood estimation in nonlinear mixed effects models. Comput. Statist. Data Anal. 2005; 1020-1038.

42 Altman DG, Bland JM. Statistical notes: diagnostic tests 1: sensitivity and specificity. BMJ. 1994; 308: 1552. 
43 Bishop YM, Fienberg SE, PW Holland. Discrete multivariate analysis: theory and practice. The MIT Press, 1977. 


\section{FIGURES AND TABLES}
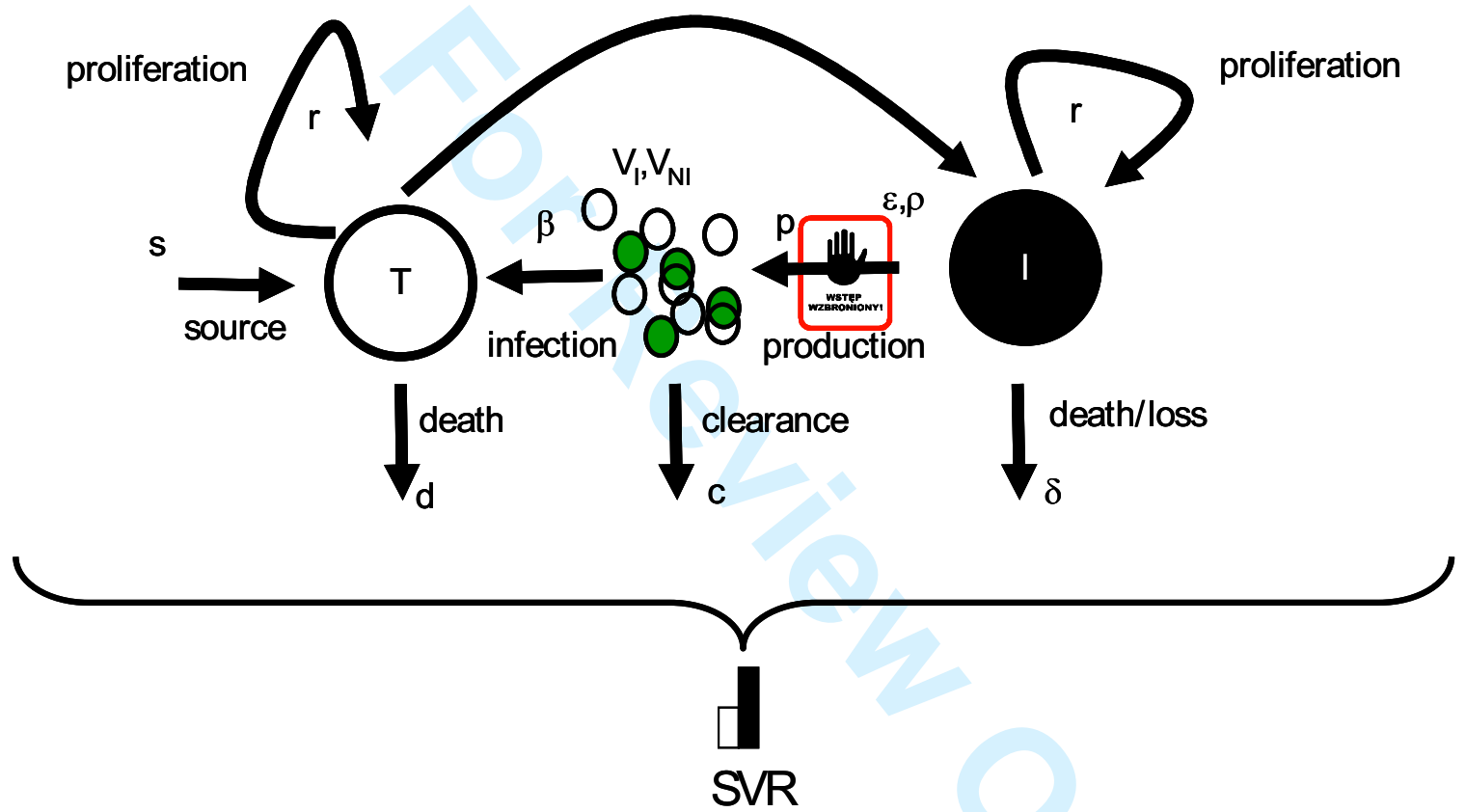

Figure 1. Representation of the extended HCV viral kinetic model. Infectious HCV virions $\left(V_{I}\right)$ infect target cells $(T)$, creating productively infected hepatocytes $(I)$. Uninfected hepatocytes $(T)$ are produced at rate $s$ and die at rate $d$. Infected hepatocytes die at rate $\delta$. A density dependent proliferation of hepatocytes (r) is assumed. Infectious $\left(V_{I}\right)$ and noninfectious $\left(V_{N I}\right)$ virions are produced at rate $p$ and cleared at rate $c$. Peginterferon $\alpha-2 \mathrm{a}$ dosedependently inhibits the production of new virions $(\varepsilon)$, and ribavirin dose-dependently renders a fraction of newly produced virions non-infectious $(\rho)$. SVR, defined as an undetectable viral load at 24 weeks after treatment completion, is the primary clinical endpoint desired to be predicted in the treatment of Hepatitis C. 


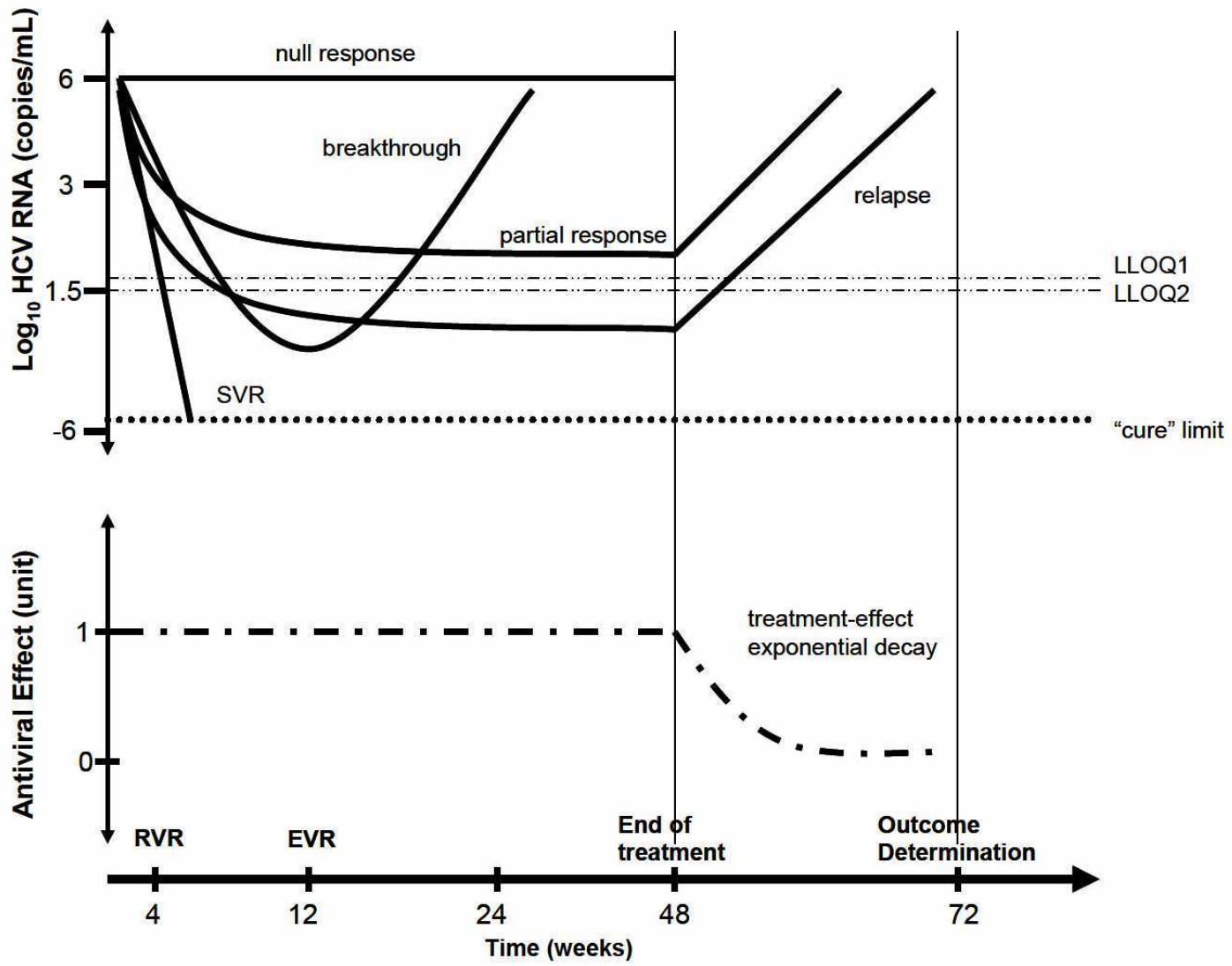

Figure 2. The viral kinetic model characterizes the complexity and diversity of clinically observed $\mathrm{HCV}$ viral kinetics in Hepatitis $\mathrm{C}$ virus patients treated with peginterferon $\alpha$-2a alone or in combination with ribavirin, and links the kinetics to clinical outcome. This is achieved by the implementation of a viral eradication cure boundary and incorporation of left-censored data, previously largely excluded from analysis, from simultaneous analysis of a wide spectrum of peginterferon $\alpha-2 \mathrm{a} \pm$ ribavirin treatment regimens from 2,100 patients. RVR and EVR are rapid virologic response and early virologic response, respectively. 

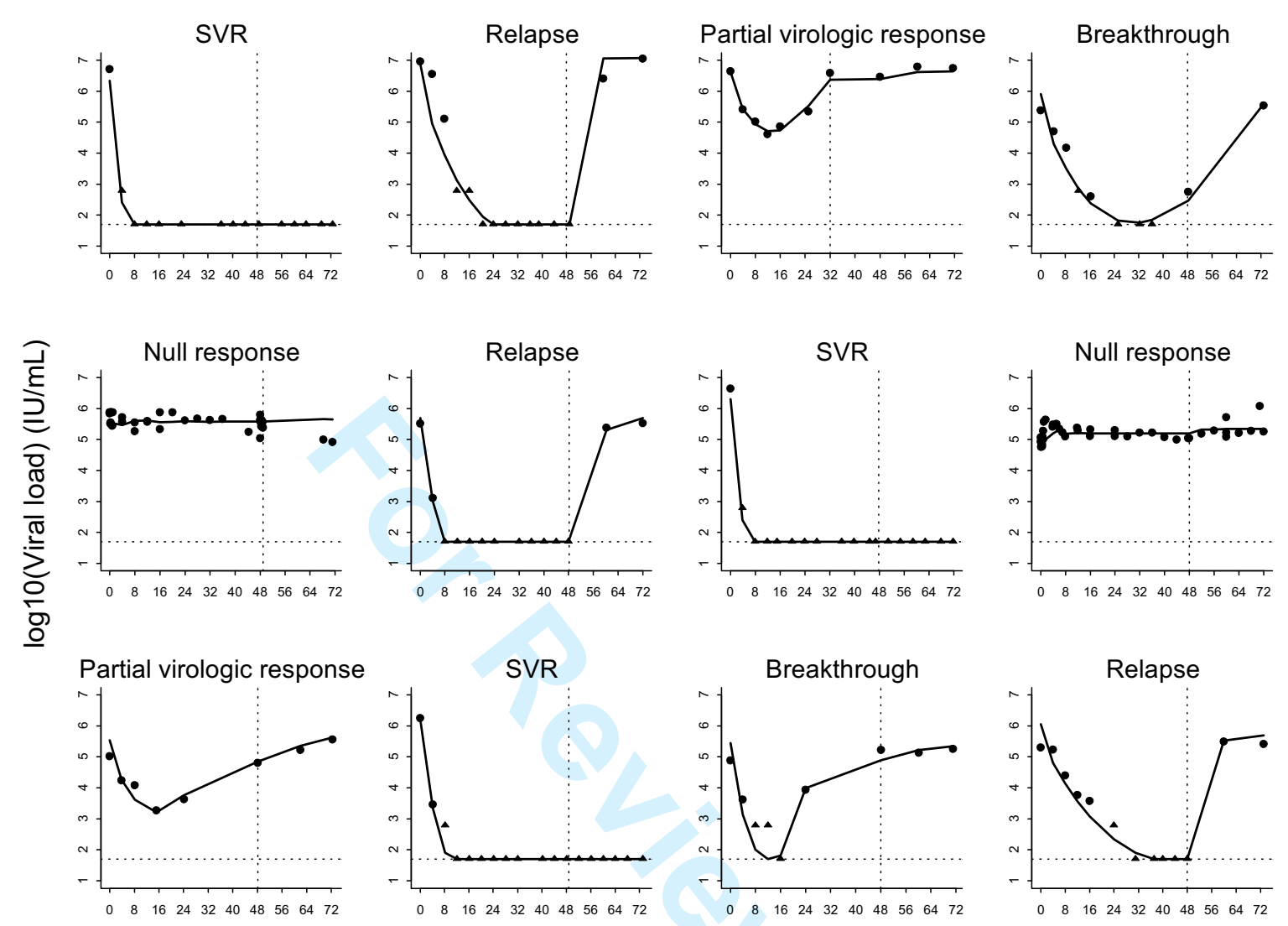

Weeks

Figure 3. Observed and model-predicted long-term viral load profiles in 12 representative $\mathrm{CHC}$ patients. Solid lines are the fits of the model to the individual viral load data which are either detectable (closed circles) or below the LLOQ of $50 \mathrm{IU} / \mathrm{mL}$ (closed triangles). Dotted horizontal lines show the LLOQ of the assay. Dotted vertical lines indicate the end of treatment. Our HCV viral kinetic model is able to describe all the typical phenomena observed after long-term therapy such as null response (no change in viral load), partial virologic response (initial decrease followed by increase during treatment), breakthrough during therapy (non-detectable viral load followed by increase during treatment), relapse after therapy (nondetectable viral load at the end of therapy followed by an increase during the treatment-free follow-up period), and SVR (non-detectable viral load at 24 weeks after end of therapy). 
A
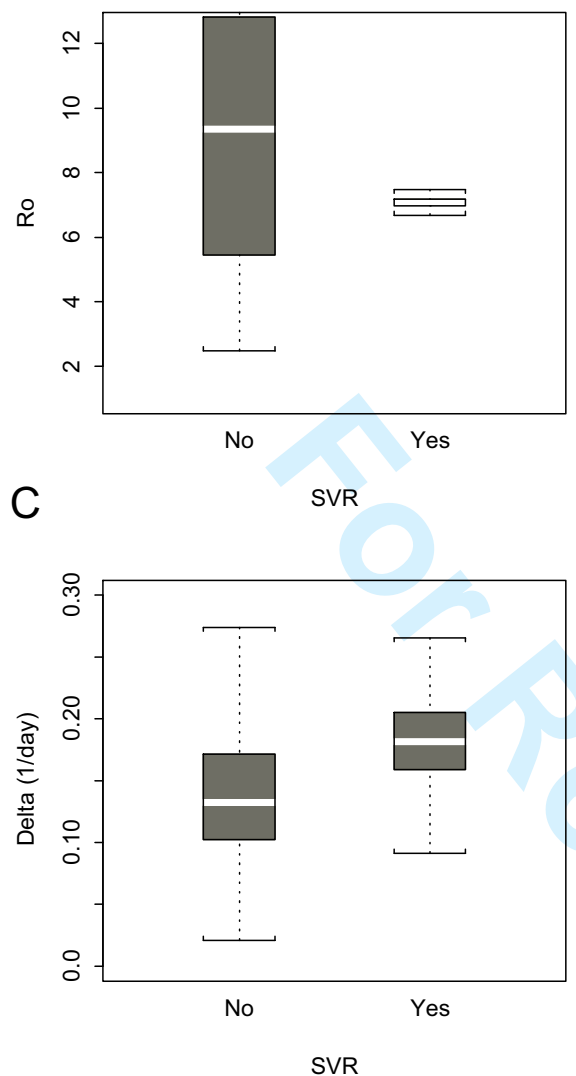

B
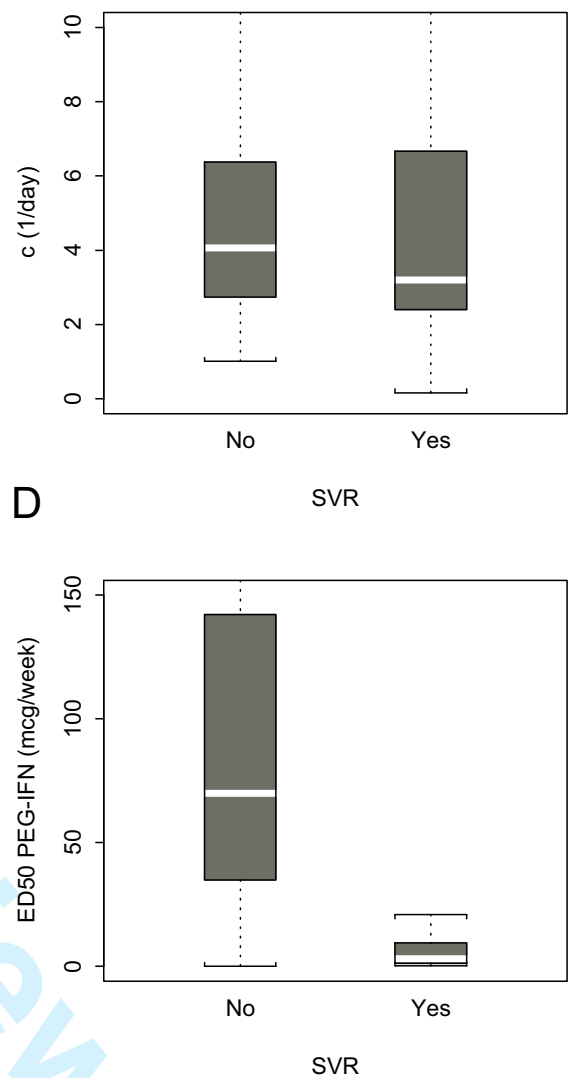

Figure 4. Boxplots of the individual $\mathrm{HCV}$ viral kinetic model parameters as split by patient outcome (i.e. SVR $(\mathrm{n}=974)$ versus non-SVR $(\mathrm{n}=1,126)$ patients). The basic reproduction number $\left(R_{0}\right)$ is generally higher and more variable in patients without an SVR $(\mathbf{A})$. The free virion clearance rate $(c)$ is not different between patients with and without an SVR (B). The infected cell death rate $(\delta)$ is generally higher in patients with an SVR $(\mathbf{C})$, and the effectiveness of peginterferon $\alpha-2 \mathrm{a}$ in inhibiting the production of new virions is generally higher in patients with an SVR (D). 
A

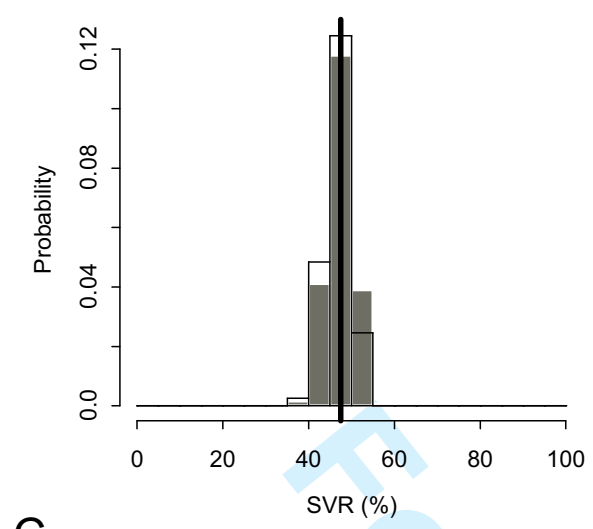

C

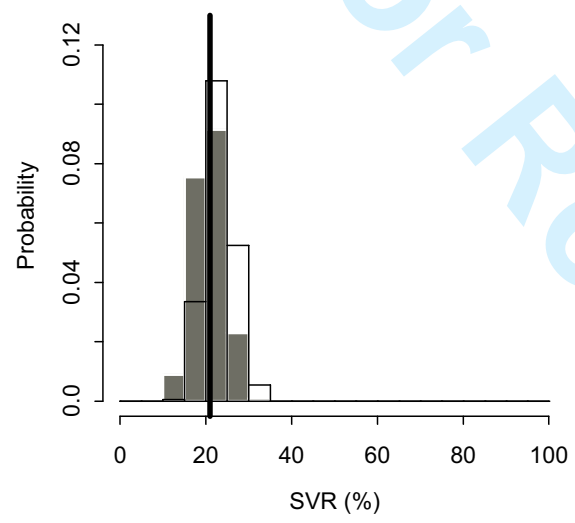

B

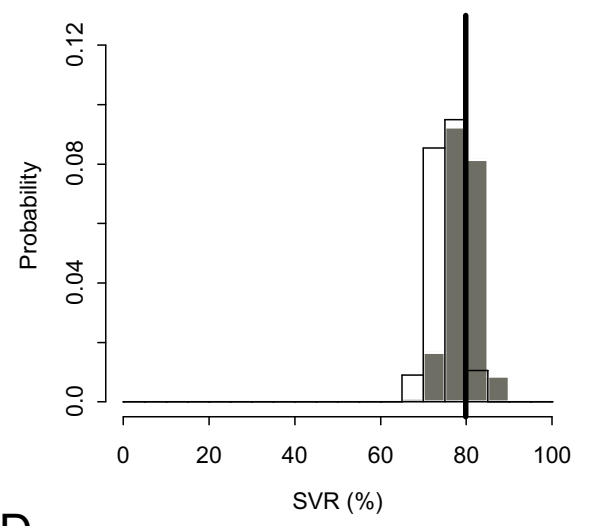

D

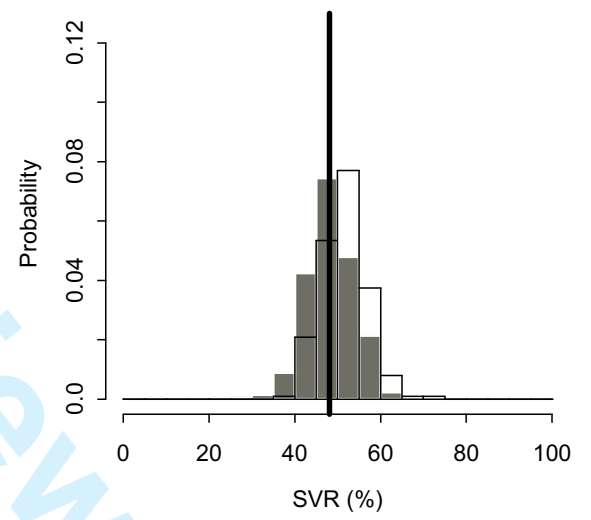

Figure 5. Observed (black vertical lines) and model predicted SVR rates (transparent histogram) of the phase-III study by Fried et al. (4), investigating $180 \mu \mathrm{g}$ peginterferon $\alpha-2 \mathrm{a}$ once weekly for 48 weeks given alone or in combination with daily 1,000 or $1,200 \mathrm{mg}$ ribavirin. Dropouts have been taken into account in the predictions by randomly assigning patients as dropout and defining them as non-SVR. The uncertainty of the observed SVR rates was quantified by 400 bootstrap samples (grey histograms). The observed SVR rate in 297 HCV G1 patients receiving combination therapy falls within the range of model predicted SVR rates (A). The observed SVR rate in $154 \mathrm{HCV}$ Gn1 patients receiving combination therapy also falls within the range of model predicted SVR rates (B). The observed SVR rate in $143 \mathrm{HCV}$ G1 patients receiving monotherapy of peginterferon $\alpha$-2a falls within the range of model predicted SVR rates (C). Finally, also the observed SVR rate in $77 \mathrm{HCV}$ Gn1 patients receiving monotherapy of peginterferon $\alpha-2$ a falls within the range of model predicted SVR rates $(\mathbf{D})$. 
Table 1. Population parameters of the HCV viral kinetic model fitted to the individual long-term viral load profiles of $2,100 \mathrm{CHC}$ patients receiving chronic treatment of peginterferon $\alpha-2 \mathrm{a}$ alone or in combination with ribavirin ${ }^{*}$. The upper part of the table represents the fixed parameters according to our assumptions, the middle part are system-specific parameters and the lower part are the drug-specific parameters. The SE reflects the precision of the estimated parameters and IIV represents the inter-individual variability (Supplementary text note 5 online).

\begin{tabular}{|c|c|c|c|c|c|}
\hline Parameter & Description & Unit & Typical value & $\mathrm{SE}(\% \mathrm{CV})^{* * *}$ & IIV $(\% \mathrm{CV})$ \\
\hline$T_{\max }$ & Total amount of hepatocytes per $\mathrm{mL}$ & hepatocytes $\cdot \mathrm{mL}^{-1}$ & $18.5 \cdot 10^{6}$ & & \\
\hline$s$ & Hepatocyte production rate & hepatocytes $\cdot \mathrm{mL}^{-1} \cdot$ day $^{-1}$ & $61.7 \cdot 10^{3}$ & & \\
\hline$d$ & Hepatocyte death rate constant & day $^{-1}$ & 0.003 & & \\
\hline$r$ & Hepatocyte proliferation rate constant & day $^{-1}$ & 0.00562 & 22 & \\
\hline$R_{0}^{* * * *}$ & Basic reproductive number & & 7.15 & 9 & 137 \\
\hline$p$ & Virion production rate & virions $\cdot$ hepatocyte ${ }^{-1}$ day $^{-1}$ & 25.1 & 15 & \\
\hline$c$ & Virion elimination rate constant & day $^{-1}$ & 4.53 & 15 & 120 \\
\hline$\delta_{H C V \text { non-1 }}$ & Infected cell death rate constant (HCVGn1) & day $^{-1}$ & 0.192 & 16 & $58^{*}$ \\
\hline$\delta_{H C V-1}$ & Infected cell death rate constant (HCV G1) & day $^{-1}$ & 0.139 & 3 & $58^{*}$ \\
\hline$E D_{50_{P E G} H C V \text { non- } 1}$ & $E D_{50}$ of peginterferon $\alpha-2 \mathrm{a}(\mathrm{HCV} \mathrm{Gn} 1)$ & $\mu \mathrm{g} \cdot$ week $^{-1}$ & 1.19 & 17 & $281^{*}$ \\
\hline$E D_{50_{P E G} H C V-1}$ & $E D_{50}$ of peginterferon $\alpha-2 \mathrm{a}(\mathrm{HCV}$ genotype-1) & $\mu \mathrm{g} \cdot$ week $^{-1}$ & 20.9 & 10 & $281^{*}$ \\
\hline$E D_{50_{R B V}}$ & $E D_{50}$ of ribavirin & $\mathrm{mg} \cdot \mathrm{kg}^{-1} \cdot \mathrm{day}^{-1}$ & 14.4 & 18 & \\
\hline$K$ & Anti-viral effect decay constant & day $^{-1}$ & 0.0238 & 13 & \\
\hline$\sigma^{2}$ & Residual error & & 0.260 & 1 & \\
\hline
\end{tabular}

* $47 \%$ received monotherapy of peginterferon $\alpha-2 \mathrm{a}$ at a weekly subcutaneous dose of $45 \mu \mathrm{g}$ (20 patients), $90 \mu \mathrm{g}$ (114 patients), $135 \mu \mathrm{g}$ (210 patients), $180 \mu \mathrm{g}$ (596 patients) or $270 \mu \mathrm{g}$ (38 patients). The CHC patients receiving combination therapy were administered a subcutaneous dose of $180 \mu \mathrm{g} / \mathrm{week}$ peginterferon $\alpha-2 \mathrm{a}$ and a daily dose of $800 \mathrm{mg}$ or 1,000/1,200 mg ribavirin. Almost all patients (93\%) received 24 weeks of treatment or more, and $61 \%$ of CHC patients received 48 weeks of treatment or more.

** Assumed to be similar between HCV genotype-1 and non-1 infected patients.

As $T_{\max }, s$ and $d$ were fixed, no SE is provided.

$R_{0}^{* * * *}$ is defined as the number of newly infected cells that arise from one infected cell when almost all cells are uninfected and has therefore no units. 


\section{Supplementary text note 1: additional model component for HCV virion} eradication

Exploratory simulations were undertaken based on the HCV viral kinetic model as described by equations 1-6 of the manuscript. An evaluation of the simulated viral load profiles of the $\mathrm{CHC}$ patient population revealed that the viral load in all patients rapidly returned back to baseline within approximately 4 to 8 weeks after stopping the 48 -week treatment (Figure S1). This implies that an SVR cannot be described without adding a model component for $\mathrm{HCV}$ virion eradication. A subsequent simulation based on the same model where only one infected cell $(I)$ remained at the end of treatment showed again a rapid return to baseline within approximately 4 weeks (Figure S2). As the virion production $p$ should cease when all infected hepatocytes are cleared, parameter $p$ was set to zero (off state) during the model fitting procedure when the number of infected hepatocytes crossed the $<1$ cell or $<1 / 13500$ cells $\cdot \mathrm{mL}^{-1}$ cure boundary condition.

\section{Supplementary text note 2: basic reproduction number $\left(\boldsymbol{R}_{\boldsymbol{0}}\right)$}

The basic reproduction number of an infection is defined as the number of newly infected hepatocytes that arise from one infected cell when almost all cells are infected, i.e. prior to treatment initiation $(S 1)$. When $R_{0}<1$, the infection will be spontaneously

cleared in the long run. But if $R_{0}>1$, the infection will be able to expand. When $R_{0}=1$, the infection will not be cleared or expand but remain at some quasi-disease equilibrium. Using a simple PK-PD model for proliferative systems, it can be shown that the reproduction number in the presence of an inhibitor of the virion production $\left(R_{T}\right)$ is $(S 2)$ :

$$
R_{T}=R_{0} \cdot\left(1-\varepsilon_{T}\right)
$$


where $\varepsilon_{T}$ is the total treatment-induced inhibition of the virion production. The infection in the presence of an inhibitor will die out in case $R_{T}<1(S 2) . R_{0}$ thus carries information on the status of infection, whereas $R_{T}$ carries information about treatment effect and the likelihood of cure.

Simulations based on our HCV viral kinetic model confirmed the previous findings based on the simple PK-PD model for proliferative systems (Figure S3). The total drug effectiveness $\varepsilon_{T}$ combined with $R_{0}$ are thus important predictors for successful drug therapy. For this reason, our model was parameterized in terms of $R_{0}$, by using the following equation for $R_{0}(S 3)$ :

$$
R_{0}=\frac{p \cdot \beta \cdot s}{c \cdot \delta \cdot d}
$$

In our model, the parameters $d$ and $s$ are assumed to be respectively $1 / 300$ day $^{-1}$ and $61.7 \cdot 10^{3}$ cells $\cdot \mathrm{mL}^{-1}$ days $^{-1}$, whereas $R_{0}, c, p$ and $\delta$ are estimated so that the de novo infection rate constant $\beta$ can be calculated.

\section{Supplementary text note 3: liver proliferation rate $(r)$}

The liver is a unique organ as it self-heals by regeneration as opposed to repair. The exact cellular and molecular mechanisms of liver regeneration are still not yet fully understood $(S 4, S 5)$. The Neumann HCV viral kinetic model was extended with a density-dependent liver proliferation term to describe the liver regeneration (S6). For liver regeneration in healthy liver donors, the liver regrowth can be described in a similar way:

$$
\frac{d T}{d t}=s+r \cdot T \cdot\left(1-\frac{T}{T_{\max }}\right)-d \cdot T
$$

$\mathrm{T}$ represents the number of hepatocytes in cells $\cdot \mathrm{mL}^{-1}$. The maximum number of hepatocytes present in an individual liver $\left(T_{\max }\right)$ is assumed to be $18.5 \cdot 10^{6}$ cells $\cdot \mathrm{mL}^{-1}$. 
The death rate of hepatocytes $(d)$ is assumed to be $1 / 300$ day $^{-1}$, and the production of new hepatocytes $(s)$ is thus $61.7 \cdot 10^{3}$ cells $\cdot \mathrm{mL}^{-1}$ days ${ }^{-1}$ from steady-state assumptions. Simulations of the liver regeneration based on the above mentioned equation and the model estimated a maximum liver proliferation rate $(r)$ of $0.006 \mathrm{day}^{-1}$, and also revealed a rapid initial liver regrowth (Figure S4). For a donor remnant liver volume of $50 \%$, the total liver volume was predicted to be approximately $89 \%$ after 360 days. This predicted total liver volume matched well with the increase in original liver volume as measured over a 1-year time period in 51 donors who provided right-lobe liver grafts $(S 7)$.

\section{Supplementary text note 4: goodness of fit assessment}

As anticipated, a diagnostic plot of the observed viral load values (DV) versus the population predictions (PRED) [Figure S5] is neither intuitive nor very informative. Because of the wide diversity of the various viral load profiles (Figure 3 of manuscript), the population based diagnostic plots have limited meaning for the assessment of the goodness of fit. In principle, the population prediction would be the same for a null-responder, a breakthrough patient, a patient having a relapse and a SVR patient. This implies that conditional estimates of the model parameters should be taken into account for model diagnostics based on population predictions to make sense. A plot of the population weighted residuals (WRES) versus PRED [Figure S6] shows a certain pattern which can be well explained by comparing the time course of the population predicted viral load with the individual viral load values. In order to assess the expected pattern of the DV versus PRED and WRES versus PRED plots of our model, mirror plots were created in which "observations" were simulated three times from the final model and these "observations" were subsequently re-fitted to create the PRED and WRES plots based on the parameters used in the simulation (Figures S5- 
S6). The patterns of the PRED- and WRES-based diagnostics for the observed and simulated data were similar, implying that the observed pattern of these two populationbased diagnostic plots matched with the expected pattern for our model (S8).

As population based diagnostics were not very infomative, goodness of fit was assessed based on diagnostic plots for the individual predictions (IPRED) [Figure S7], individual weighted residuals (IWRES) [Figure S8] and the absolute values of the individual weighted residuals (IIWRESI) [Figure S9]. The $\varepsilon$-shrinkage was calculated to be 9\%, implying that individual predictions can be used as a reliable diagnostic (S8). Mirror plots were also created for IPRED, IWRES and IIWRESI (Figures S7-S9). The patterns of the goodness of fit plots for IPRED, IWRES and IIWRESI for the observed and simulated data were similar, implying that no model misspecification was evident from the diagnostic (S8), and thus indicating that the individual viral load profiles are well described by the model. In addition, the goodness of fit plot of IIWRESI versus IPRED indicates that the residual error model was appropriate.

The $\eta$-shrinkage was calculated to be $39 \%$ for the basic reproduction number $\left(R_{0}\right), 17 \%$ for the free virion clearance rate $(c), 31 \%$ for the infected cell death rate $(\delta)$ and $34 \%$ for $E D_{50_{P E G}}$. As anticipated, the relatively high shrinkage values are driven by the typical viral load profiles of the different patient categories (i.e. null-responders, breakthrough patients, relapsing patients and patients having an SVR). For instance, the shrinkage of $\delta$, describing the second phase of the viral load decay, was only $4 \%$ in breakthrough patients and $17 \%$ in patients having a relapse. These two patient categories generally have a relatively slow decay of the viral load so that the individual values of $\delta$ can be well estimated. SVR-patient viral load decline was generally characterized by a fast decay so that the second phase is not always visible, while null or partial responding 
patients, had a relatively flat profile, and the $\delta$ estimate was more shrunken towards the population mean.

\section{Supplementary text note 5: performance of model-based SVR classification}

Statistical measures of the performance of the SVR classification by the HCV viral kinetic model were obtained by comparing the SVR classification (SVR or non-SVR) based on the model to the observed SVR classification in each individual patient present in the database of 2,100 CHC patients. Since by definition, the proposed model does not characterize SVR directly, but SVR is derived from crossing the model cure boundary, the performance of the model related to correctly classifying patients could be assessed by calculating the sensitivity and specificity based on individual predictions of $\mathrm{HCV}$ RNA including those obtained post-treatment $(9,10)$ without confounding bias. A total of 941 patients were found to be True Positive (observed SVR and model-predicted SVR), and 1,119 CHC patients were found to be True Negative (observed non-SVR and model-predicted non-SVR) [Table S1]. A total of 33 patients were found to be False Negative (observed SVR but model-predicted non-SVR), and 7 patients were found to be False Positive (observed non-SVR but model-predicted SVR). Based on these numbers, the sensitivity and specificity was calculated to be $96.6 \%$ and $99.4 \%$, respectively. Although the difference in the number of correctly and incorrectly classified individuals is quite convincing, it should be noted that the sensitivity and specificity are positively biased as the rows and columns of Table S1 are not fully independent. The positive predictive value (PPV) and negative predictive value (NPV) was calculated to be $99.3 \%$ and $97.1 \%$, respectively. In calculating these two statistics, it is assumed that the prevalence in the population at large is similar. 

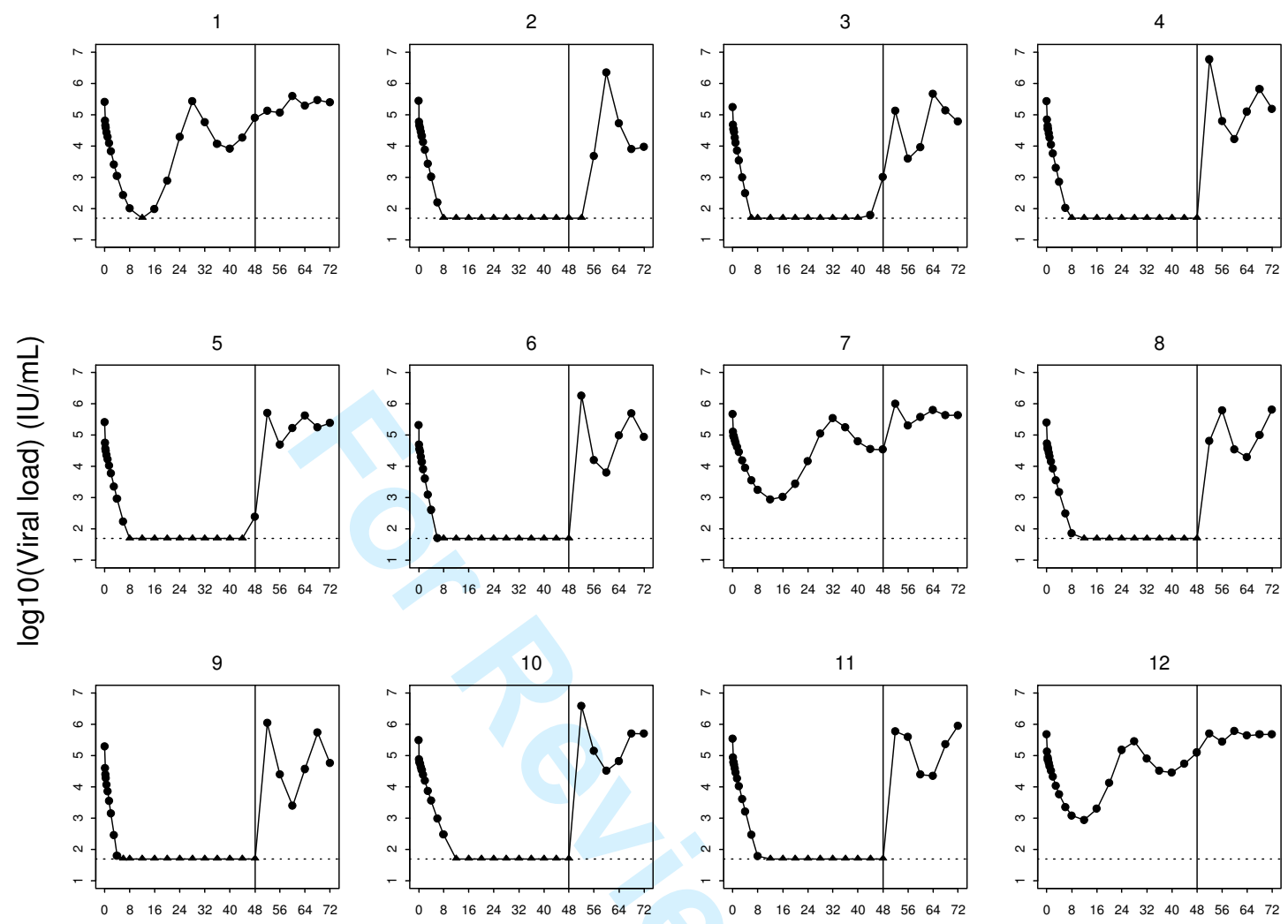

Weeks

Figure S1. Simulated long-term viral load profiles in 12 CHC patients receiving a 48week treatment. Viral load profiles were simulated assuming $R_{0}=8, p=6$ virions $^{-}$cell $^{-}$ ${ }^{1}$. day $^{-1}, c=3$ day $^{-1}, \delta=0.2$ day $^{-1}, r=0.005$ day $^{-1}$ and an inhibition of the virion production of $80 \%$. IIV was assumed to be $40 \% \mathrm{CV}$ for $R_{0}$ and $20 \% \mathrm{CV}$ for all other parameters. Simulated individual viral load data are either detectable (closed circles) or below the LLOQ of $50 \mathrm{IU} / \mathrm{mL}$ (closed triangles). Dotted horizontal lines show the LLOQ of the assay. Vertical lines indicate the end of treatment at 48 weeks. 


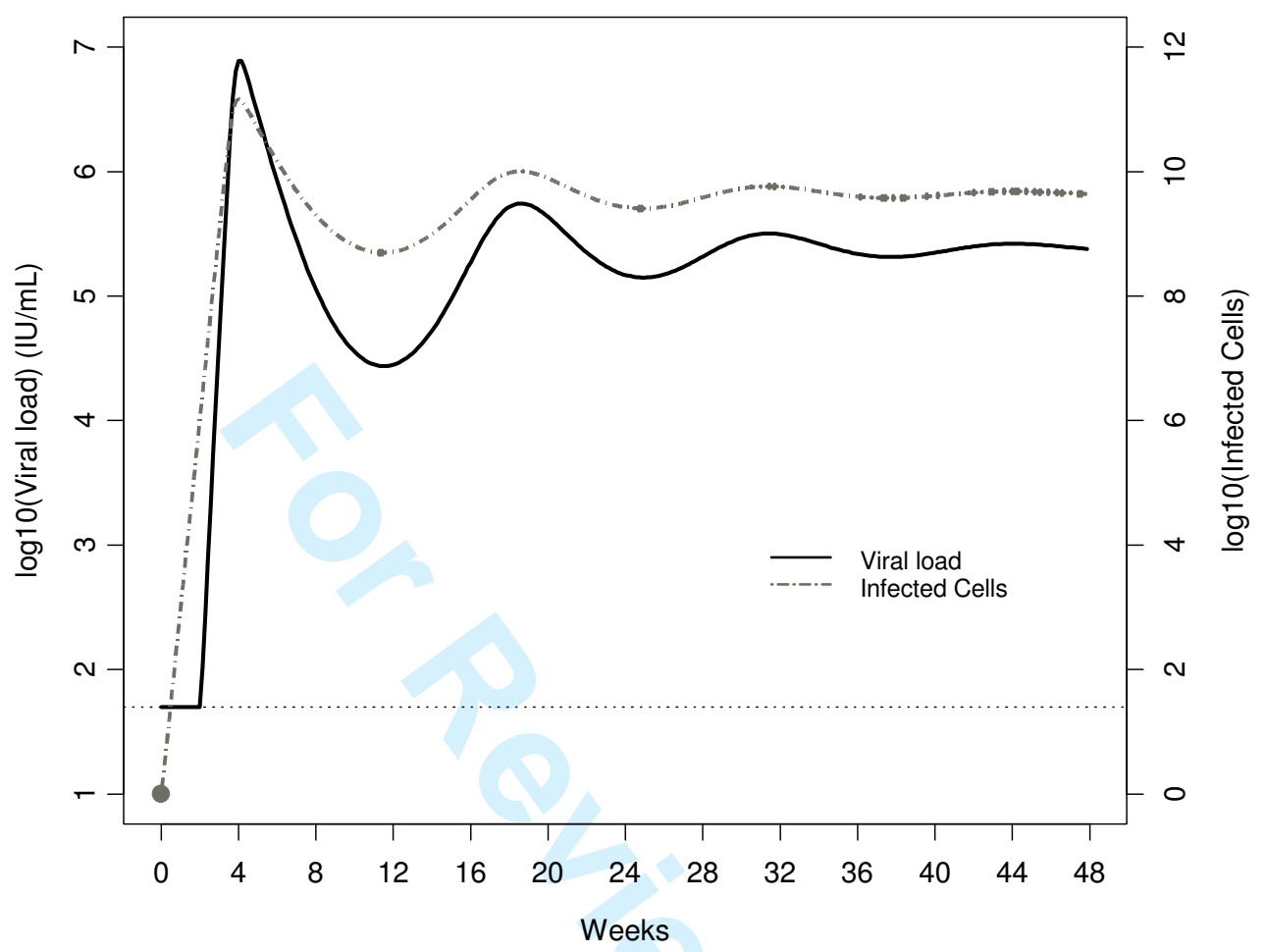

Figure S2. Simulated HCV viral load (black line) and simulated number of infected hepatocytes (grey dashed line) with only one infected cell remained at the end of treatment. The simulation was performed with $R_{0}=8, p=6$ virions $\cdot$ cell $^{-1} \cdot$ day $^{-1}, c=3$ day $^{-1}, \delta=0.2$ day $^{-1}$ and liver proliferation rate $r=0.005$ day $^{-1}$. The dotted horizontal lines show the LLOQ of the assay of $50 \mathrm{IU} / \mathrm{mL}$. 


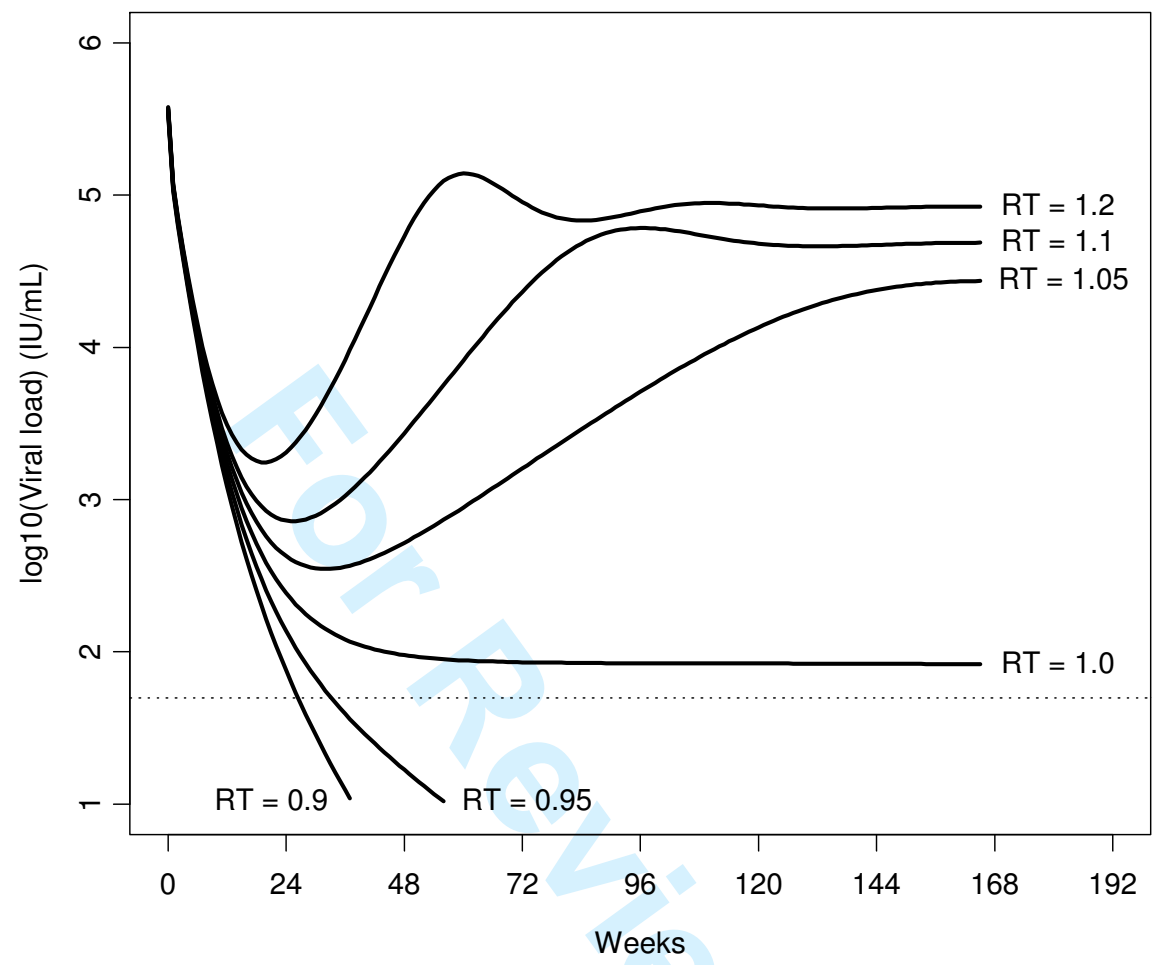

Figure S3. Simulated HCV viral load profiles during a 192-week antiviral therapy resulting in a continuous $50 \%$ inhibition of the virion production $(\varepsilon=0.5)$. Simulations were performed with $p=6$ virions cell $^{-1} \cdot$ day $^{-1}, c=3$ day $^{-1}, \delta=0.16$ day $^{-1}$ and $r=0.01$ day $^{-1}$. The dotted horizontal line shows the LLOQ of the assay of $50 \mathrm{IU} / \mathrm{mL}$. The basic reproductive number $\left(R_{0}\right)$ was assumed to be $2.4,2.2,2.1,2.0,1.9$ and 1.8 , respectively resulting in a basic reproduction number in the presence of a 50\% inhibition of the virion production $\left(R_{T}\right)$ of 1.2, 1.1, 1.05, 1.0, 0.95 and 0.9 (see equation $\mathrm{S} 1$ ). Simulations confirmed that when $R_{T}<1$, the infection will be cleared in the long run. But if $R_{T}>1$, the infection will expand. When $R_{T}=1$, the infection will not be cleared or expand but remain at some quasi-disease equilibrium. 


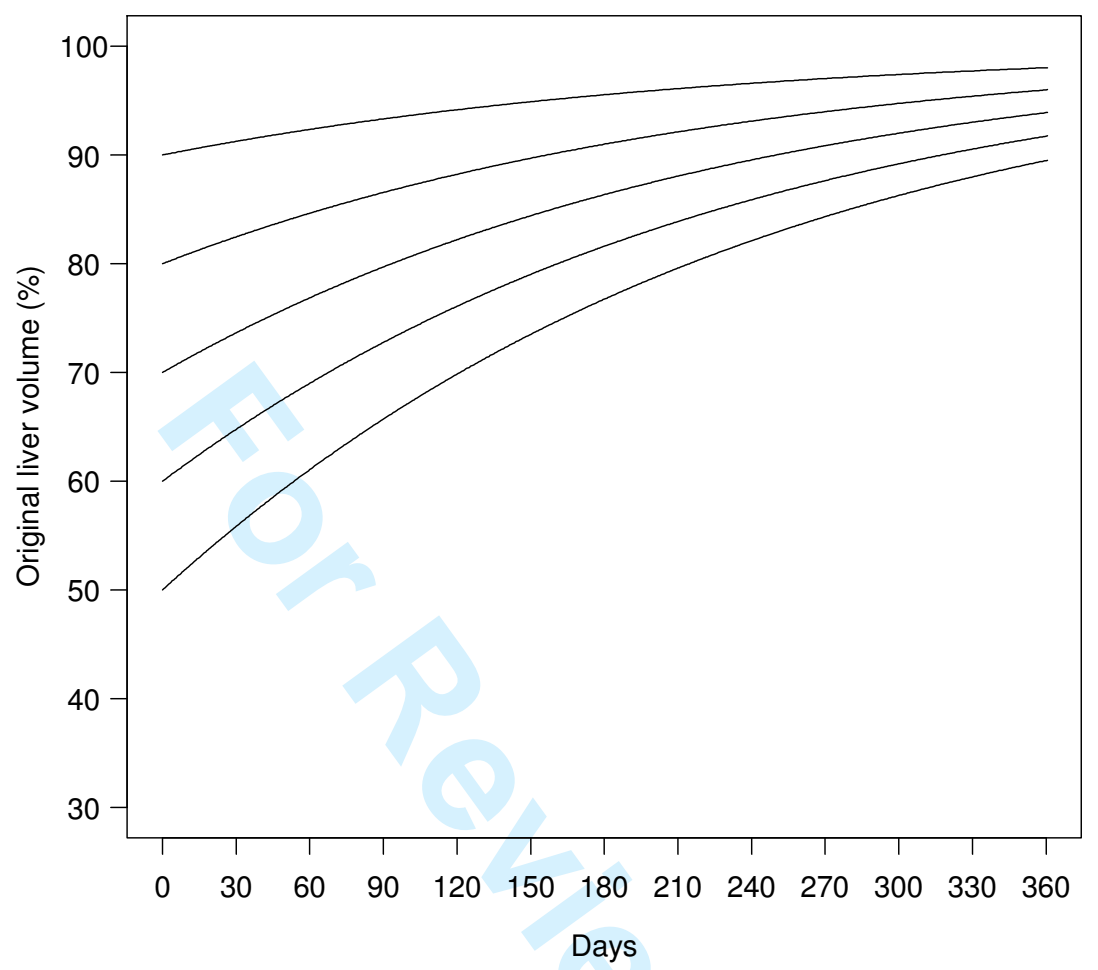

Figure S4. Simulated liver regeneration after a donor remnant liver volume of 50\%, $60 \%, 70 \%, 80 \%$ and $90 \%$ of the original total liver volume. Simulations were performed with the model estimated maximum liver proliferation rate $(r)$ of 0.006 day $^{-1}$. 
Actual Data

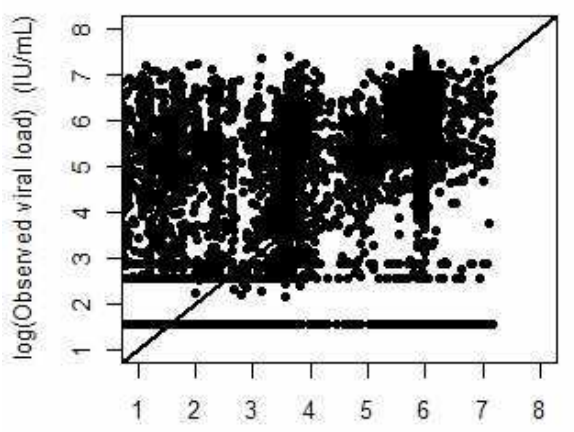

$\log ($ Population predicted viral load) (IU/mL)

Simulation 2

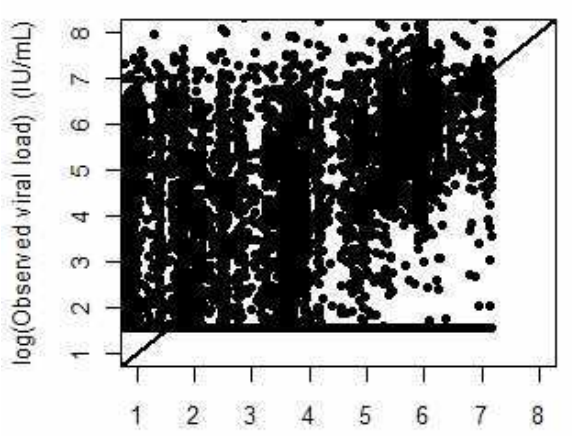

$\log ($ Population predicted viral load) $(\mathrm{IU} / \mathrm{mL})$
Simulation 1

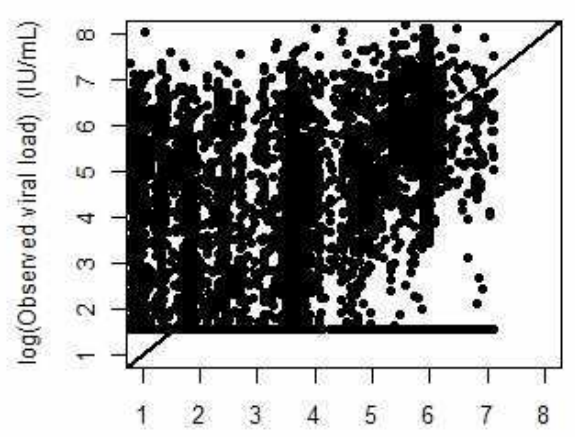

$\log ($ Population predicted viral load) $(\mathrm{IU} / \mathrm{mL})$

Simulation 3

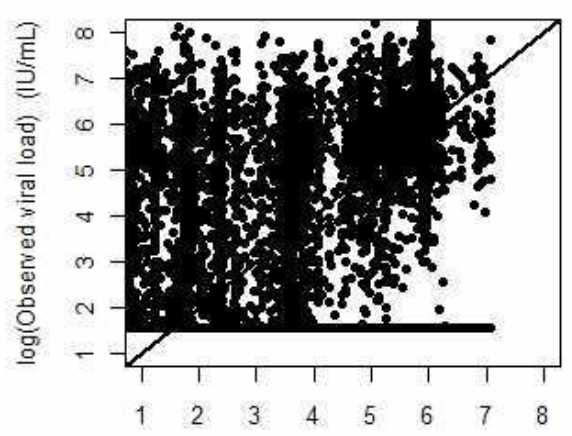

$\log ($ Population predicted viral load) $(\mathrm{IU} / \mathrm{mL})$

Figure S5. Mirror plot of the observed versus population predictions (PRED) for the HCV viral kinetic model fitted to the actual data (upper left panel) and when all "observations" are simulated three times with the same model as is used to calculate the individual predictions (upper right panel and lower panels). The predicted values are based on the estimated parameter values. The solid black line is the line of identity which should go through the middle of the data. Simulations were undertaken with an LLOQ of $50 \mathrm{IU} / \mathrm{mL}$ explaining the presence of more lower "observed" values in the simulations. 


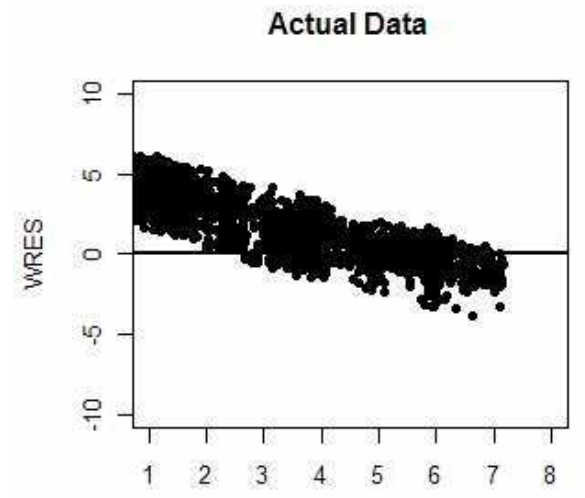

$\log ($ Population predicted viral load) (IU/mL)

Simulation 2

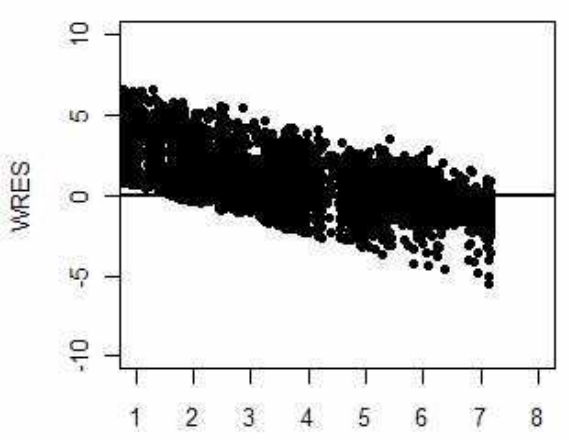

$\log ($ Population predicted viral load) $(\mathrm{IU} / \mathrm{mL})$

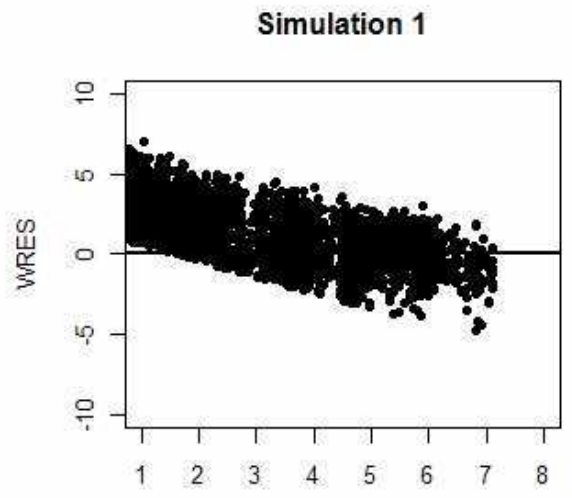

$\log ($ Population predicted viral load) (IU/mL)

Simulation 3

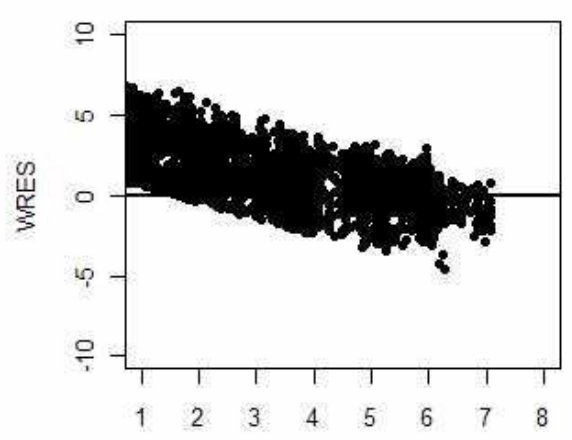

$\log$ (Population predicted viral load) $(\mathrm{IU} / \mathrm{mL})$

Figure S6. Mirror plot of the weighted residuals (WRES) versus population predictions (PRED) for the HCV viral kinetic model fitted to the actual data (upper left panel) and when all "observations" are simulated three times with the same model as is used to calculate the WRES (upper right panel and lower panels). The solid black line is the zero line. 
Actual Data

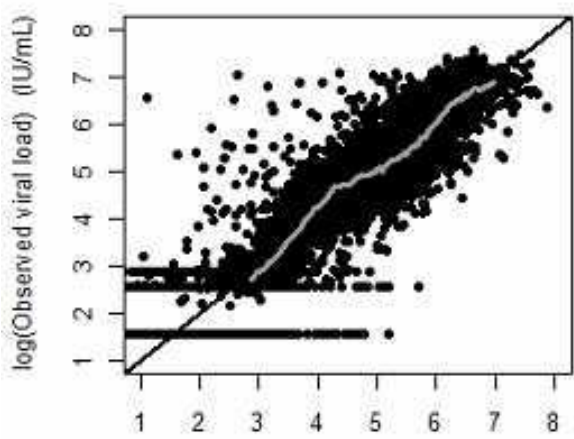

$\log ($ individual predicted viral load) (IU/mL)

Simulation 2

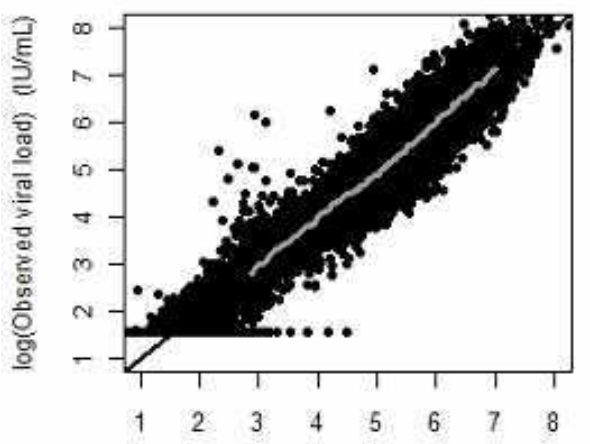

$\log ($ Individual predicted viral load) (IU/mL)
Simulation 1

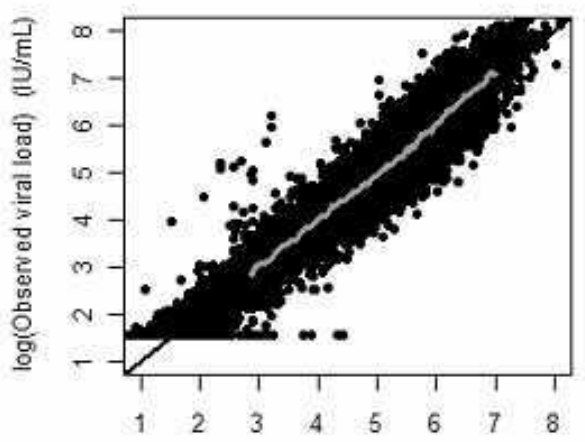

$\log (i n d i v i d u a l$ predicted viral load) (IU/mL)

Simulation 3

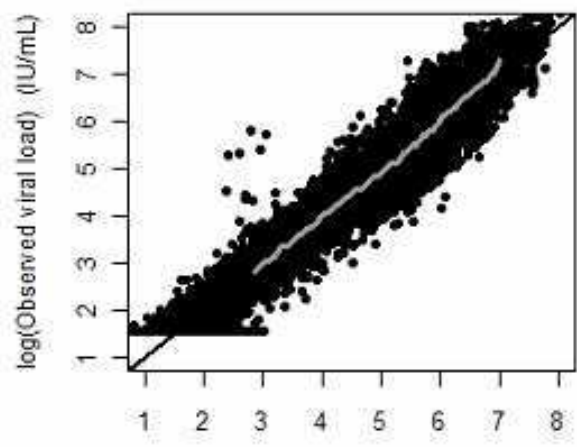

$\log ($ individual predicted viral load) $(\mathrm{IU} / \mathrm{mL})$

Figure S7. Mirror plot of the observed versus individual predictions (IPRED) for the $\mathrm{HCV}$ viral kinetic model fitted to the actual data (upper left panel) and when all "observations" are simulated three times with the same model as is used to calculate the individual predictions (upper right panel and lower panels). The predicted values are based on the estimated parameter values. The grey line represents a smooth through the data. The solid black line is the line of identity which should go through the middle of the data. Simulations were undertaken with an LLOQ of $50 \mathrm{IU} / \mathrm{mL}$ explaining the presence of more lower "observed" and IPRED values in the simulations. 


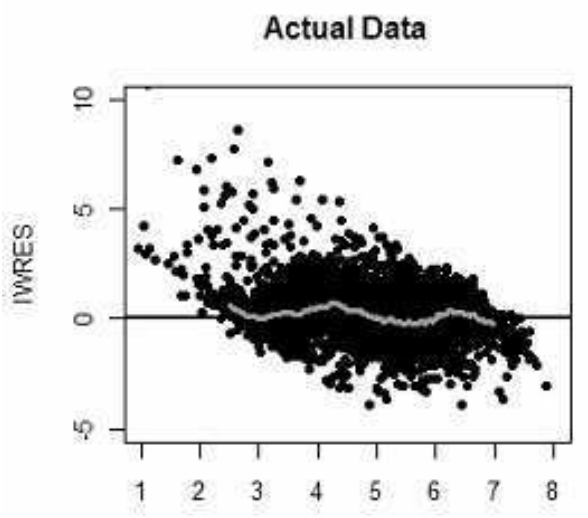

$\log ($ Individual predicted viral load) (IU/mL)

Simulation 2

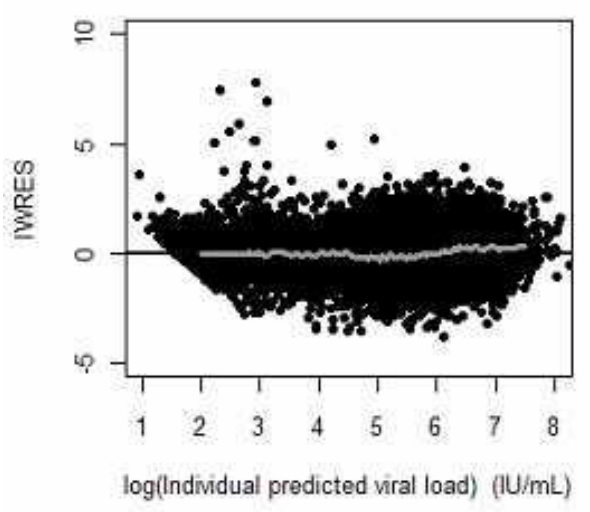

Simulation 1

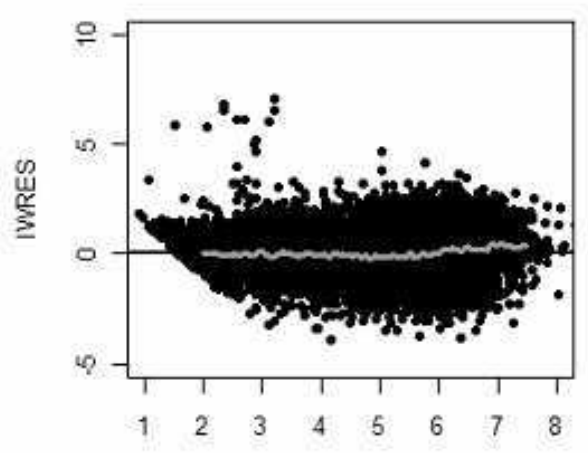

$\log ($ individual predicted viral load) (IU/mL)

Simulation 3

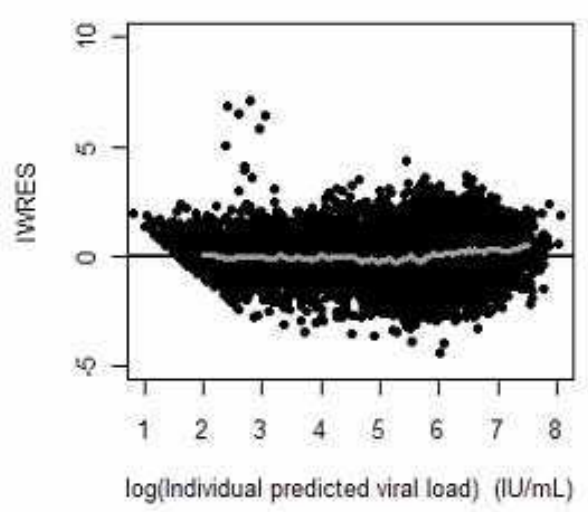

Figure S8. Mirror plot of the individual weighted residuals (IWRES) versus individual predictions (IPRED) for the HCV viral kinetic model fitted to the actual data (upper left panel) and when all "observations" are simulated three times with the same model as is used to calculate the IWRES (upper right panel and lower panels). The grey line represents a smooth through the data. The solid black line is the zero line around which the values of IWRES should be randomly and densely scattered. Simulations were undertaken with an LLOQ of $50 \mathrm{IU} / \mathrm{mL}$ explaining the presence of more lower IPRED values in the simulations. Some higher IWRES values are present for small IPRED values based on the actual data. However, these data points present only a minor fraction of the overall data. 


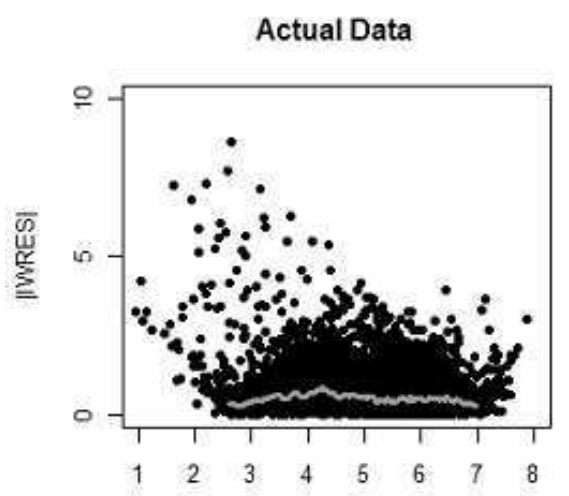

$\log ($ Individual predicted vral load) (IU/mL)

Simulation 2

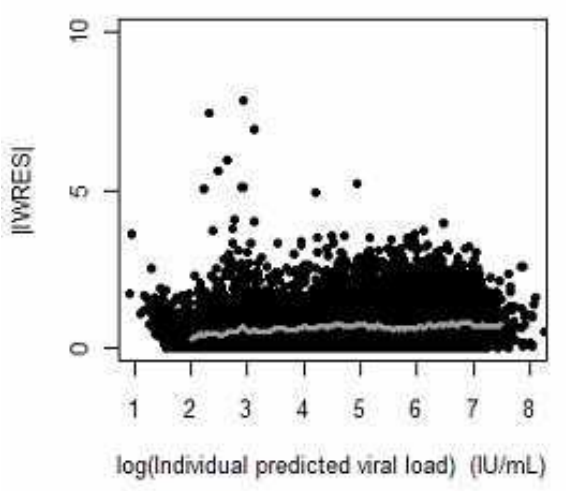

Simulation 1

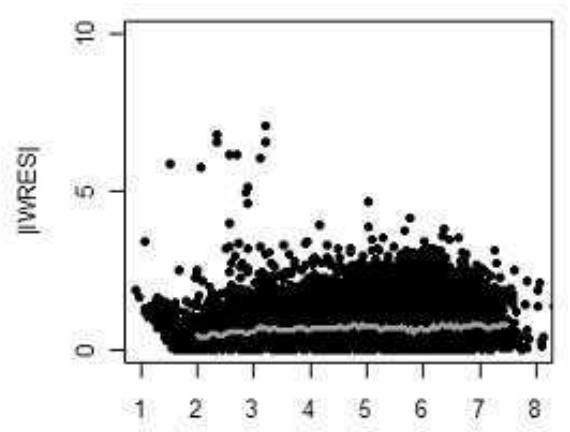

$\log ($ individual predicted viral load) $(\mathrm{IU} / \mathrm{mL})$

Simulation 3

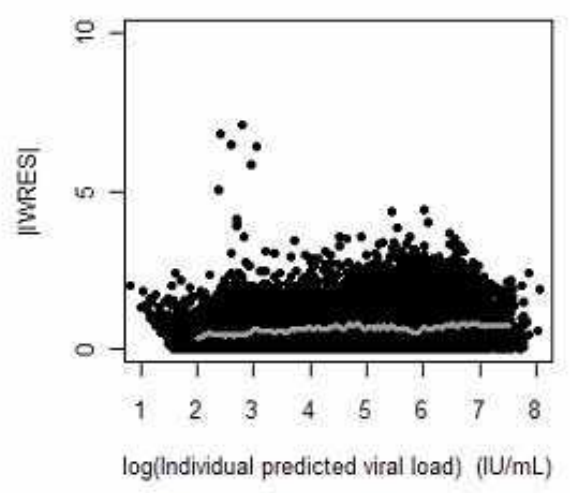

Figure S9. Mirror plot of the absolute values of the individual weighted residuals (IIWRESI) versus individual predictions for the HCV viral kinetic model fitted to the actual data (upper left panel) and when all "observations" are simulated three times with the same model as is used to calculate the IIWRESI (upper right panel and lower panels). Simulations were undertaken with an LLOQ of $50 \mathrm{IU} / \mathrm{mL}$ explaining the presence of more lower IPRED values in the simulations. Some higher IIWRESI values are present for small IPRED values based on the actual data. However, these data points present only a minor fraction of the overall data. 
Table S1. Calculation of the sensitivity, specificity, positive predictive value (PPV) and negative predictive value (NPV) for the model-based classification of CHC patients into SVR or non-SVR.

\begin{tabular}{|c|c|c|c|c|}
\hline & \multicolumn{2}{|c|}{ Observed SVR } & \multirow{2}{*}{ Total } \\
\hline & & $\mathrm{SVR}=1$ & $\mathrm{SVR}=0$ & \\
\hline \multirow{3}{*}{ Fitted SVR } & $\mathrm{SVR}=1$ & $\begin{array}{c}\text { True Positive } \\
941\end{array}$ & $\begin{array}{c}\text { False Positive } \\
7 \\
\end{array}$ & $\begin{array}{c}948 \\
\mathrm{PPV}^{3}=99.3 \%\end{array}$ \\
\hline & $\mathrm{SVR}=0$ & $\begin{array}{c}\text { False Negative } \\
33 \\
\end{array}$ & $\begin{array}{c}\text { True Negative } \\
1119 \\
\end{array}$ & $\begin{array}{c}1152 \\
\mathrm{NPV}^{4}=97.1 \%\end{array}$ \\
\hline & Total & $\begin{array}{c}974 \\
\text { Sensitivity }^{1}=96.6 \%\end{array}$ & $\begin{array}{c}1,126 \\
\text { Specificity }^{2}=99.4 \%\end{array}$ & 2,100 \\
\hline
\end{tabular}

${ }^{1}$ Sensitivity is calculated as 941 divided by 974 and expressed as $\%$.

${ }^{2}$ Specificity is calculated as 1,119 divided by 1,126 and expressed as $\%$.

${ }^{3}$ Positive predicted value (PPV) is calculated as 941 divided by 948 and expressed as $\%$.

${ }^{4}$ Negative predictive value (NPV) is calculated as 1,119 divided by 1,152 and expressed as $\%$. 


\section{References for supporting online material}

1 Heffernan JM, Smith RJ, Wahl LM. Perspectives on the basic reproductive ratio. J R Soc Interface. 2005 Sep 22;2(4):281-93.

2 Jacqmin P et al., submitted for publication in J. Pharmacokinet. Pharmacodyn.

3 Callaway DS, Perelson AS. HIV-1 infection and low steady state viral loads. Bull Math Biol. 2002 Jan;64(1):29-64.

4 Michalopoulos GK, DeFrances MC. Liver regeneration. Science. 1997 Apr 4;276(5309):60-6.

5 Khan AZ, Mudan SS. Liver regeneration: mechanisms, mysteries and more. ANZ J. Surg. 2007;77:9-14.

6 Dahari H, Lo A, Ribeiro RM, Perelson AS. Modeling hepatitis C virus dynamics: liver regeneration and critical drug efficacy. J Theor Biol. 2007 Jul 21;247(2):371-81. Epub 2007 Mar 14.

7 Pomfret EA, Pomposelli JJ, Gordon FD, Erbay N, Lyn Price L, Lewis WD, Jenkins RL. Liver regeneration and surgical outcome in donors of right-lobe liver grafts. Transplantation. 2003 Jul 15;76(1):5-10.

8 Karlsson MO, Savic RM. Diagnosing model diagnostics. Clin Pharmacol Ther 2007;82(1):17-20.

9 Altman DG, Bland JM. Statistical notes: diagnostic tests 1: sensitivity and specificity. BMJ. 1994; 308: 1552.

10 Bishop YM, Fienberg SE, PW Holland. Discrete multivariate analysis: theory and practice. The MIT Press, 1977. 